\title{
CAMA
}

Centre for Applied Macroeconomic Analysis

\section{Forecasting GDP with global components. This time is different}

\section{CAMA Working Paper 26/2016 May 2016}

Hilde C. Bjørnland

Centre for Applied Macro- and Petroleum economics (CAMP) - BI Norwegian Business School

Norges Bank and

Centre for Applied Macroeconomic Analysis, ANU

\section{Francesco Ravazzolo}

Centre for Applied Macro- and Petroleum economics (CAMP) - BI Norwegian Business

School

Norges Bank and

Centre for Applied Macroeconomic Analysis, ANU

\section{Leif Anders Thorsrud}

Centre for Applied Macro- and Petroleum economics (CAMP) - BI Norwegian Business School

\begin{abstract}
We examine whether knowledge of in-sample co-movement across countries can be used in a more systematic way to improve forecast accuracy at the national level. In particular, we ask if a model with common international business cycle factors adds marginal predictive power compared to a domestic alternative? To answer this question we use a Dynamic Factor Model (DFM) and run an out-of-sample forecasting experiment. Our results show that exploiting the informational content in a common global business cycle factor improves forecast accuracy in terms of both point and density forecast evaluation across a large panel of countries. We also document that the Great Recession has a huge impact on this result, causing a clear preference shift towards the model including a common global factor. However, this time is different also in other respects. On longer forecasting horizons the performance of the DFM deteriorates substantially in the aftermath of the Great Recession.
\end{abstract}




\section{Keywords}

Bayesian Dynamic Factor Model (BDFM), forecasting, model uncertainty and global factors

\section{JEL Classification}

C11, C53, C55, F17

\section{Address for correspondence:}

(E) cama.admin@anu.edu.au

\section{ISSN 2206-0332}

The Centre for Applied Macroeconomic Analysis in the Crawford School of Public Policy has been established to build strong links between professional macroeconomists. It provides a forum for quality macroeconomic research and discussion of policy issues between academia, government and the private sector.

The Crawford School of Public Policy is the Australian National University's public policy school, serving and influencing Australia, Asia and the Pacific through advanced policy research, graduate and executive education, and policy impact. 


\title{
Forecasting GDP with global components. This time is different*
}

\author{
Hilde C. Bjørnland ${ }^{\dagger} \quad$ Francesco Ravazzolo ${ }^{\ddagger}$ \\ Leif Anders Thorsrud ${ }^{\S}$
}

December 30, 2015

\begin{abstract}
We examine whether knowledge of in-sample co-movement across countries can be used in a more systematic way to improve forecast accuracy at the national level. In particular, we ask if a model with common international business cycle factors adds marginal predictive power compared to a domestic alternative? To answer this question we use a Dynamic Factor Model (DFM) and run an out-of-sample forecasting experiment. Our results show that exploiting the informational content in a common global business cycle factor improves forecast accuracy in terms of both point and density forecast evaluation across a large panel of countries. We also document that the Great Recession has a huge impact on this result, causing a clear preference shift towards the model including a common global factor. However, this time is different also in other respects. On longer forecasting horizons the performance of the DFM deteriorates substantially in the aftermath of the Great Recession.
\end{abstract}

JEL-codes: C11, C53, C55, F17

Keywords: Bayesian Dynamic Factor Model (BDFM), forecasting, model uncertainty and global factors

${ }^{*}$ The authors would like to thank seminar and conference participants at PBC School of Finance at Tsinghua University, CAMA at Australia National University, the 22nd Symposium of the Society for Nonlinear Dynamics and Econometrics in New York and the CEF 2014 annual conference in Oslo for valuable comments. This paper is part of the research activities at the Centre for Applied Macro and Petroleum economics (CAMP) at the BI Norwegian Business School. The usual disclaimers apply. The views expressed in this paper are those of the authors and do not necessarily reflect the views of Norges Bank.

${ }^{\dagger}$ Centre for Applied Macro- and Petroleum economics (CAMP) - BI Norwegian Business School, Centre for Applied Macroeconomic Analysis (CAMA) - Australian National University and Norges Bank. Email: hilde.c.bjornland@bi.no

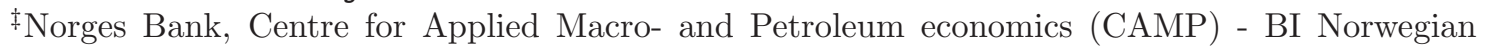
Business School and Centre for Applied Macroeconomic Analysis (CAMA) - Australian National University. Email: francesco.ravazzolo@norges-bank.no

$\S$ Centre for Applied Macro- and Petroleum economics (CAMP) - BI Norwegian Business School. Email: leif.a.thorsrud@bi.no 


\section{Introduction}

A long strand of literature has shown that the co-movement of aggregate activity across a large number of countries can be reasonably well explained by one (or a few) common business cycle factors. For example, in Kose et al. (2003) up to 35 percent of the variance in domestic GDP across G7 countries is attributed to one common international business cycle factor. ${ }^{1}$ Imbs (2010) provides further evidence. Focusing on the distribution of business cycles, he shows that the Great Recession was a true global recession, the first in decades.

However, knowledge of in-sample co-movement across countries, in particular during recessions, does not necessarily imply predictability. As is now well known, the Great Recession (2007-2009) turned out to be hard to predict, with private and public sector forecasters across the world committing large forecast errors relative to their historical performance, c.f. Stockton (2012) and Alessi et al. (2014) for a discussion of the forecast performance of the Bank of England, Federal Reserve Bank of New York and the European Central Bank. A common explanation for this forecast failure has been the high level of uncertainty at the time. Neither the size or timing of the shocks that hit the global economy had been foreseen. Nor was the extent of the propagation of these shocks into economic activity. Consistent with this, many recent papers have shown that forecast errors typically rise dramatically in severe recessions when uncertainty is high, c.f., Baker et al. (2013), and most notably during the Great Recession, see Jurado et al. (2015). ${ }^{2}$

Our purpose is to examine whether knowledge of in-sample co-movement across countries could have been used in a more systematic way to improve forecast accuracy at the national level. As claimed by, e.g., Ashley et al. (1980), in-sample inference without out-of-sample verification is likely to be spurious, with an out-of-sample approach inherently involving less over-fitting. Hence, an out-of sample evaluation seems a natural next step in light of the in-sample evidence of co-movement across countries (reported in, e.g., Imbs (2010)), and the massive forecast failures across the world prior to the Great Recession. This paper therefore asks: Could a model with common international business cycle factors add marginal predictive power in an out-of-sample forecasting experiment?

To examine whether common international components add value in terms of forecasting, we specify a Dynamic Factor Model (DFM) widely used for studying international business cycle synchronization. Our dataset contains quarterly real GDP growth from 1978 to 2011 for 33 countries across the world, broadly covering 4 geographical regions and both developed and emerging economies. The out-of-sample forecasting experiment starts in 1991:Q1. For each new vintage of data the DFM is re-estimated and forecasts produced, generating a total of 82 out-of-sample forecast observations for each country. The factor model forecasts are compared to forecasts produced by a simple autoregressive process. In our experiment this is the natural benchmark model,

\footnotetext{
${ }^{1}$ Corroborated theoretical and empirical findings are reported in, e.g., Ambler et al. (2002), Stock and Watson (2005b), Baxter and Kouparitsas (2005), Backus and Kehoe (1992), Backus et al. (1995) and Engel and Wang (2011).

${ }^{2}$ More generally, GDP is often found to be hard to predict, and it has been difficult to beat simple $\operatorname{AR}(p)$ or random walk models, see, e.g., Stock and Watson $(1999,2002)$. Furthermore, the predictability of more complex models relative to naive forecasts seems to have declined since the 1980s, see D'Agostino et al. (2006).
} 
(a) Covariance

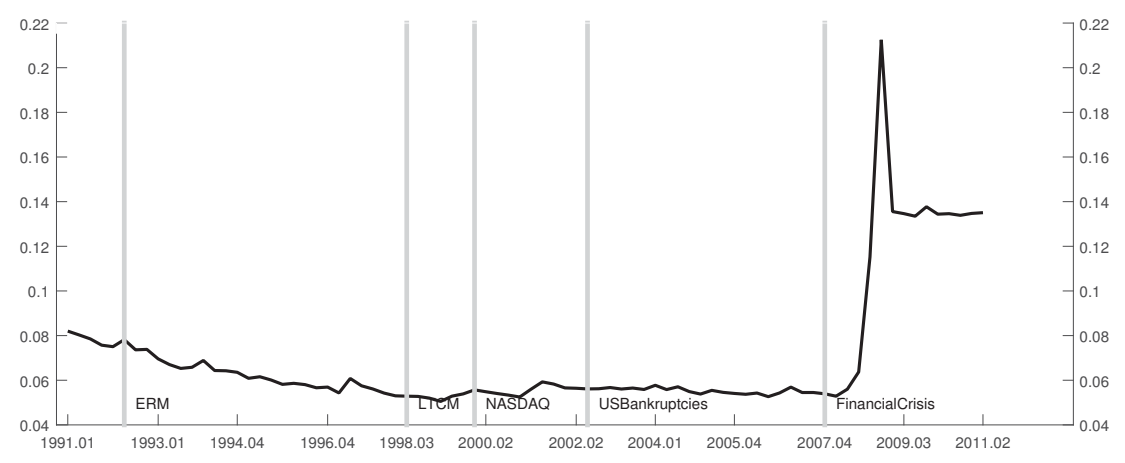

(b) Variance

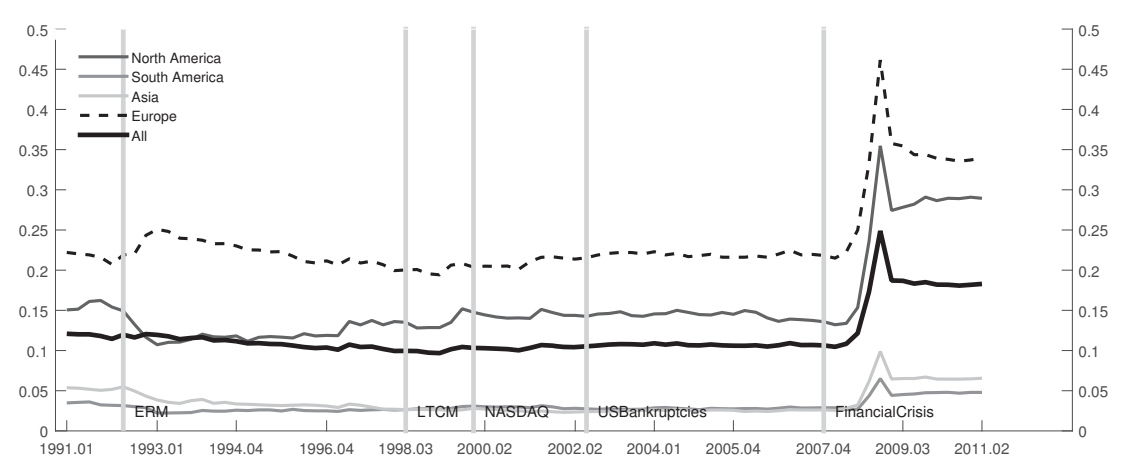

Figure 1. In-sample evidence. Figure 1a (1b) reports the recursively estimated covariance (variance) as implied by the Dynamic Factor Model and one common global business cycle factor, see Section 2 for a detailed description of the model. The covariance (variance) is reported as the average of all elements below (on) the diagonal in the covariance matrix at each point in time. The variance is reported as a fraction of the total variance explained by the model. In addition, Figure $1 \mathrm{~b}$ reports the average within different regional clusters.

as the DFM we employ collapses to an autoregressive process for each country if the common factors are irrelevant. ${ }^{3}$ We evaluate predictability in terms of both point and density forecasts across time, employing mean squared errors (MSE) and continuous ranked probability score (CRPS) scoring functions. In particular, we examine whether predictability increased in the recent financial crisis relative to previous recessions and global events.

The DFM we use is similar to the factor models used in other business cycle synchronization studies. For this reason, we would expect the model to also confirm the earlier in-sample evidence alluded to above - and it does. In line with the results reported in Imbs (2010), the Great Recession had a huge impact on business cycle synchronization, increasing the covariance across countries explained by one common business cycle factor considerably, see Figure 1a. Much of this increased covariance can be attributed to an increase in overall volatility in the period around the Great Recession. This is seen in Figure 1b, which reports the variance explained attributed to the common business cycle factor. Overall, the variance explained attributed to

\footnotetext{
${ }^{3}$ Admittedly, in a pure forecasting horse-race, other benchmark models could be harder to outperform. In addition, when assessing predictability across 33 countries, the best benchmark model would almost surely vary considerably across countries. However, running a horse-race is not our intention. Our focus is to address if the evidence from the in sample business cycle synchronization literature could be used to add marginal predictive power in an out-of-sample forecasting setting.
} 
the common factor is not large, but for countries in Europe and North America it is substantial. ${ }^{4}$ As such, the figure also highlights another important feature found in the more recent business cycle synchronization literature, namely that the world is not enough: When explaining business cycle synchronization, common regional factors seem to matter more and more relative to one common global factor, see, e.g., Crucini et al. (2011), Mumtaz et al. (2011) and Thorsrud (2013). In this paper, after investigating the marginal predictive power of a common global business cycle factor, we therefore expand the factor set to also control for such common regional developments.

Our out-of-sample forecasting experiment delivers the following results: First, exploiting the information content in a common global business cycle factor improves forecasting accuracy in terms of both point and density forecast evaluation across a large panel of countries. In particular, we find that the forecasts produced by the standard DFM on average (across countries) adds marginal predictive power to the natural benchmark, an autoregressive process for each individual country.

Second, in line with the in-sample evidence reported above, we also document that the Great Recession has a huge impact on this result. Irrespective of which loss function we use, the event causes a clear preference shift towards the model including a common global factor. Similar shifts are not observed earlier in the evaluation sample. This is in particular interesting in light of the recent evidence of heightened uncertainty and increased forecast errors during deep recessions, c.f. Baker et al. (2013) and Jurado et al. (2015). In our out-of sample forecasting experiment the information content in the common global component now works to reduce the forecast errors (relative to the benchmark) and hence increase forecasting accuracy.

However, this time is different also in other respects. On longer forecasting horizons the performance of the DFM deteriorates substantially in the aftermath of the Great Recession. To the extent that forecast errors are a good proxy for uncertainty, this indicates that during the recession, information about common movements could have worked to reduce uncertainty across countries, while during the recovery phase use of such knowledge would in fact have increased it. Augmenting the DFM with regional factors (including, e.g., an Asia-specific business cycle factor) alleviates this uncertainty somewhat: It improves the short-term forecasting performance of the model further, and gives out-of-sample support to the in-sample studies advocating the importance of regional business cycle factors.

Studying country specific details, we confirm the importance of regional factors. In particular, we show that it is the developed countries (the US and most European countries) that benefited the most from the DFM going into the financial crisis. Although the short term forecast performance of the emerging countries (including commodity exporters) also increase, the gain is less than for the developed countries. On the other hand, we find that going out of the recession, the relative long term forecast performance falls by much more for the developed countries than for the emerging and commodity exporting countries. A common pattern of high growth rates in many Asian and South American countries in the aftermath of the financial crisis may suggest why these countries benefit from adding common factors to the DFM. In contrast,

${ }^{4}$ Even for countries in these regions the numbers are somewhat smaller than those reported in, e.g., Kose et al. (2003). One reason for this is likely the fact that we look at quarterly growth rates, while they use yearly numbers that contain much less noise. 
uncertainty related to economic policies in the US and Europe in particular, see, e.g., Baker et al. (2013), could explain some of the recent forecast failure in these regions.

The rest of the paper is organized as follows: In Section 2 we describe the DFM, the data, and the out-of-sample forecasting experiment. In Section 3 we report our results. We start with our main evaluation using a DFM with one global component only. We then report the results for the augmented model, including regional factors, and the results for the individual countries. Section 4 concludes.

\section{Model, estimation and out-of-sample evaluation}

The Dynamic Factor Model (DFM) we use is frequently employed in the business cycle synchronization literature, and particularly useful in a data rich environment such as ours, where common latent factors and shocks are assumed to drive the co-movements across a large cross section of countries.

Formally, the DFM can be formulated as in equations (1) and (2):

$$
y_{t}=\lambda_{0} f_{t}+\epsilon_{t}
$$

where the $N \times 1$ vector $y_{t}$ represents the observables at time $t$. $\lambda_{0}$ is a $N \times q$ matrix of factor loadings, $\epsilon_{t}$ is an $N \times 1$ vector of idiosyncratic errors, and the dynamic factors follow a $\operatorname{VAR}(\mathrm{h})$ process:

$$
f_{t}=\phi_{1} f_{t-1}+\cdots+\phi_{h} f_{t-h}+u_{t}
$$

Here, $u_{t}$ is a $q \times 1$ vector of VAR(h) errors, which are assumed to be independent from the idiosyncratic errors in (1):

$$
\left[\begin{array}{l}
\epsilon_{t} \\
u_{t}
\end{array}\right] \sim \text { i.i.d.N }\left(\left[\begin{array}{l}
0 \\
0
\end{array}\right],\left[\begin{array}{cc}
R & 0 \\
0 & Q
\end{array}\right]\right)
$$

The co-movement among the observable variables is described by the common factors. For the idiosyncratic errors we consider the case where $\epsilon_{t, i}$, for $i=1, \cdots, N$, follows independent $\mathrm{AR}(\mathrm{l})$ processes:

$$
\epsilon_{t, i}=\rho_{1, i} \epsilon_{t-1, i}+\cdots+\rho_{l, i} \epsilon_{t-l, i}+\omega_{t, i}
$$

where $l$ denotes the number of lags, and $\omega_{t, i}$ is the $\operatorname{AR}(1)$ residuals with $\omega_{t, i} \sim$ i.i.d. $N\left(0, \sigma_{i}^{2}\right)$. I.e.:

$$
R=\left[\begin{array}{cccc}
\sigma_{1}^{2} & 0 & \cdots & 0 \\
0 & \sigma_{2}^{2} & \ddots & 0 \\
\vdots & \ddots & \ddots & \vdots \\
0 & \cdots & \cdots & \sigma_{N}^{2}
\end{array}\right]
$$

To separately identify the factors and the loadings, and to be able to give the factors an economic interpretation, we enforce the following identification restrictions on equation (1):

$$
\lambda_{0}=\left[\begin{array}{c}
\lambda_{0,1} \\
\lambda_{0,2}
\end{array}\right]
$$


where $\lambda_{0,1}$ is a $q \times q$ identity matrix, and $\lambda_{0,2}$ is left unrestricted. As shown in Bai and $\mathrm{Ng}$ (2013) and Bai and Wang (2015), these restrictions uniquely identify the dynamic factors and the loadings, but leave the VAR(h) dynamics for the factors completely unrestricted. See also the discussion in Section 3.2.

To keep the model as close to the ones used in the traditional in-sample business cycle synchronization literature as possible, a number of restrictions have been enforced which all might hamper the model fit as well as forecast performance. First, we do not allow for lagged dependence on the dynamic factor in the observation equation of the system. Allowing for such non contemporaneous relationships are often found to be supported by the data, see, e.g., Bjørnland and Thorsrud (2015), but to our knowledge less seldom used in the business cycle synchronization literature. Second, neither the volatility of the shocks, nor the factor loadings, are allowed to change across time. As found in newer factor model studies by, e.g., Negro and Otrok (2008), and a large literature on the Great Moderation, allowing for changes in the size of shocks, in particular, seems to be an important feature of the data. ${ }^{5}$ Finally, by restricting the idiosyncratic errors to be independent from each other, we enforce all co-movement between the observables to be driven by the common component(s). If this restriction is wrong, an approximate DFM, which allows for weak correlation among the idiosyncratic errors given the factors, would be a more appropriate model. In a frequentist setting, Stock and Watson (2005a) discusses a number of statistics that can be used to test for this (see, e.g., Lopes and West (2004) for a related discussion in a Bayesian setting), including the potential solution given by expanding the factor space. This is the route we follow here: In Sections 3.2 and 3.3 we compare the performance, and discuss the economic significance, of varying the number of factors to include in the DFM when running the out-of-sample predictive experiment.

\section{$2.1 \quad$ Data}

Our data set is composed of real Gross Domestic Product (GDP) for 33 countries, which together account for roughly 80 percent of world GDP. The data are collected from the GVAR '2011 Vintage' data set constructed by Gang Zhang, Ambrogio Cesa Bianchi, and Alessandro Rebucci at the Inter-American Development Bank. The cross section of GDP data covers the countries: Argentina, Australia, Austria, Belgium, Brazil, Canada, Chile, China, Finland, France, Germany, India, Indonesia, Italy, Japan, Korea, Malaysia, Mexico, The Netherlands, New Zealand, Norway, Peru, Philippines, Saudi Arabia, Singapore, South Africa, Spain, Sweden, Switzerland, Thailand, Turkey, the United Kingdom, and the United States.

The data span the time period 1978:Q1 to 2011:Q2. Prior to estimation, all data are made stationary by taking the logarithmic difference, and demeaned.

Table 3, in Appendix A, reports descriptive statistics for the 33 countries under study. As seen in the table there is large, and well known, heterogeneity across countries. Mean GDP growth is higher (above median) for most emerging Asian countries and some commodity exporters (i.e., Australia, Brazil, Mexico, Norway and Peru), and lower for G8 economies. Moreover, volatility is higher for small open economies

\footnotetext{
${ }^{5}$ Still, the parameters of the model are re-estimated every period as we move through the out-ofsample forecasting sample, see Section 2.3. They are nevertheless assumed to be Gaussian within each estimation window, ruling out fat tails etc.
} 
(i.e., Norway and Sweden) and for most Asian and South American countries and lower for G8 and most other European countries.

\subsection{Model specification and estimation}

In the baseline scenario we specify a factor model including only one global business cycle factor. That is, we set $q=1$ and identify it as a global business cycle factor by letting US GDP be the first variable in the observable $y_{t}$ vector. Accordingly, the global business cycle factor loads with one on US GDP growth. As described in greater detail below, we later expand the model to include up to $q=4$ business cycle factors to accommodate potential regional specific developments. For all specifications we let the number of lags in the transition equation equal two $(h=2)$, and the number of lags for the idiosyncratic auto-regressions equal one $(l=1)$.

Let $\tilde{y}_{T}=\left[y_{1}, \cdots, y_{T}\right]^{\prime}$ and $\tilde{f}_{T}=\left[f_{1}, \cdots, f_{T}\right]^{\prime}$, and define $H=\lambda_{0}, \beta=\left[\phi_{1}, \cdots, \phi_{h}\right]$, $\mathrm{Q}, \mathrm{R}$, and $p_{i}=\left[\rho_{1, i}, \cdots, \rho_{l, i}\right]$ for $i=1, \cdots, N$, as the model's hyper-parameters. Inference on the unknown states and hyper-parameters is based on Bayesian estimation of the state space model using Gibbs simulation, where the following three steps are iterated until convergence is achieved: Step 1: Conditional on the data $\left(\tilde{y}_{T}\right)$ and all the parameters of the model, generate $\tilde{f}_{T}$. Step 2: Conditional on $\tilde{f}_{T}$, generate $\beta$ and Q. Step 3: Conditional on $\tilde{f}_{T}$, and data for the i-th variable $\left(\tilde{y}_{T, i}\right)$, generate $H_{i}, R_{i}$ and $p_{i}$ for $i=1, \cdots, N$

In Appendix B we describe each MCMC step in greater detail, and document the employed prior specifications. Here we note that the priors are all reasonable uninformative, but still proper, and that we have experimented using other prior specifications without observing that this has material impact on the factor estimates. We simulate the model using a total of 10000 iterations. 5000 draws are used as burn-in, and only every 5 th iteration is stored and used for inference. ${ }^{6}$

\subsection{Out-of-sample forecasting and evaluation}

In constructing density and point forecasts, we use a recursive forecasting scheme, expanding the model estimation sample as forecasting moves forward in time. The target variables are specified as growth rates, and we evaluate predictions $y_{t+h}, h=1,2, \ldots, 5$, quarters into the future. We focus on the full sample period 1990:Q1-2011:Q2, a prefinancial crisis sample period 1990:Q1-2007:Q3, and the financial crisis period 2007:Q42011:Q2. We consider several evaluation statistics for point and density forecasts previously proposed in literature. The section proceeds by detailing our approaches for scoring and comparing forecasts.

We compare point forecasts in terms of Root Mean Square Prediction Errors (RMSPE):

$$
R M S P E_{k}=\sqrt{\frac{1}{t^{*}} \sum_{\tau=\underline{t}}^{\bar{t}} e_{k, \tau+h}}
$$

\footnotetext{
${ }^{6}$ Standard MCMC convergence tests confirm that the Gibbs sampler converges to the posterior distribution. Convergence statistics can be obtained on request. Due to the computational aspects of the analysis, which are rather time consuming, both the convergence tests and the alternative prior specifications have been conducted on the model estimated using the full sample.
} 
where $t^{*}=\bar{t}-\underline{t}+h, \bar{\tau}$ and $\underline{\tau}$ denote the beginning and end of the evaluation period, and $e_{k, \tau+h}$ is the square prediction error associated to the forecast made by model $k$ at time $\tau$ for the observation $y_{\tau+h}$. Following Welch and Goyal (2008) we also investigate how squared prediction errors varies over time by a graphical inspection of the Cumulative Squared Prediction Error Difference (CSPED):

$$
C S P E D_{k, \tau+1}=\sum_{s=\underline{t}}^{t} \widehat{f}_{k, s+h},
$$

where $\widehat{f}_{k, \tau+1}=e_{A R, \tau+h}-e_{k, \tau+h}$. utilizing the

Following Gneiting and Ranjan (2011), Groen et al. (2012) and Ravazzolo and Vahey (2013) for applications to inflation density forecasts, and Clark and Ravazzolo (2015) for a larger set of macro variables, we evaluate density forecasts based on the continuous rank probability score (CRPS). The CRPS for the model $k$ measures the average absolute distance between the empirical cumulative distribution function (CDF) of $y_{\tau+h}$, which is simply a step function in $y_{\tau+h}$, and the empirical CDF that is associated with model $k$ 's predictive density:

$$
\begin{array}{cc}
\mathrm{CRPS}_{k, \tau+h} & =\int\left(F(z)-\mathbb{I}_{\left[y_{\tau+h},+\infty\right)}(z)\right)^{2} \mathrm{~d} z \\
=\mathbb{E}_{t}\left|\tilde{y}_{k, t+\tau}-y_{\tau+h}\right|-\frac{1}{2} \mathbb{E}_{t}\left|\tilde{y}_{k, \tau+h}-\tilde{y}_{k, \tau+h}^{\prime}\right|,
\end{array}
$$

where $F$ is the CDF from the predictive density $p\left(\tilde{y}_{k, \tau+h} \mid y_{1: t}\right)$ of model $k$ and $\tilde{y}_{k, \tau+h}$ and $\tilde{y}_{k, \tau+h}^{\prime}$ are independent random variables with common sampling density equal to the posterior predictive density $p\left(\tilde{y}_{k, \tau+h} \mid y_{1: t}\right)$. Smaller CRPS values imply higher precisions and we report in tables the average $C R P S_{k}$ for each model $k$. Gneiting and Raftery (2007)) discuss the properties of the CRPS, including that it is a strictly proper scoring rule that can be related to Bayes factors and to cross-validation, and that it can also be used for evaluation of some areas (quantiles) of interest of the predictive density. As for the RMSPE analysis, we compute CRPS Difference (CRPSD), and plot them.

To provide a rough gauge of whether the differences in forecast accuracy are significant, we follow Clark and Ravazzolo (2015) and apply a $t$-tests variant of the Diebold and Mariano (1995) test for equality of the average loss (with loss defined as squared error or CRPS). We choose the t-test version as Monte Carlo evidence in Clark and McCracken (2011) and Clark and McCracken (2015) indicates that, with nested models, the Diebold-Mariano test can be viewed as a somewhat conservative test for equal accuracy in finite samples compared to normal critical values (conservative in the sense of tending to have size modestly below nominal size). In the tables and figures, differences in accuracy that are statistically different from zero are denoted by one or two asterisks, corresponding to significance levels of $10 \%$ and $5 \%$, respectively. The underlying $p$-values are based on $t$-statistics computed with a serial correlation-robust variance, using the pre-whitened quadratic spectral estimator of Andrews and Monahan (1992). Since our models are nested to the AR benchmark, we report $p$-values based on one-sided tests and look for rejection of the null of equal accuracy versus the alternative that the factor model is superior to the benchmark AR model. ${ }^{7}$

\footnotetext{
${ }^{7}$ The AR is estimated using Gibbs simulations, using the same priors as specified for the serially
} correlated idiosyncratic errors of the factor model, see Sections 2.2 and B.0.4. 
Finally, we evaluate the predictive densities using a test of absolute forecast accuracy. As in Diebold et al. (1998), we utilize the Probability Integral Transforms (PITS) of the realization of the variable with respect to the forecast densities. A forecast density is preferred if the density is correctly calibrated, i.e., the empirical predictive distribution matches the true, unobserved distribution that generates the data, regardless of the forecaster's loss function. The PIT at time $\tau+1$ are:

$$
\operatorname{PIT}_{k, \tau+1}=\int_{-\infty}^{y_{\tau+h}} p\left(\tilde{u}_{k, \tau+h} \mid y_{1: \tau}\right) d \tilde{u}_{k, \tau+h}
$$

and should be uniformly, independently (if $h=1$ ) and identically distributed if the forecast densities $p\left(\tilde{y}_{k, \tau+h} \mid y_{1: t}\right)$, for $\tau=\underline{t}, \ldots, \bar{t}$, are correctly calibrated. Hence, calibration evaluation requires the application of tests for goodness of fit. We apply the Berkowitz (2001) test for zero mean, unit variance and independence of the PITS. The null of the test is no calibration failure. Mitchell and Wallis (2010) discuss the value of information-based methods for evaluating forecast densities that are well calibrated on the basis of PIT tests.

\section{Results}

From Figure 1 we saw that there was co-movement between countries, in particular during the financial crisis. Our main focus here is to analyse if knowledge about such co-movement can be useful in terms of forecasting GDP growth in the individual countries, and in different periods.

We first note that the estimated global business cycle factor is very similar to what is found in comparable business cycle synchronization studies. That is, the estimated factor has characteristics associated with the global business cycle showing a decline in world activity during the early 1980s and early 1990s, following the dot-com bubble that burst in 2000/2001, and during the Great Recession. The latter trough is by far the most severe. These are all periods that correspond closely to the recessions dated by the NBER for the U.S., see Figure 7, reported in Appendix A for brevity.

Below we discuss the forecast performance of the global model for predicting GDP. In line with the in-sample business cycle synchronization literature, referred to in Section 1, we focus on average results across all countries. We then expand the model to incorporate regional business cycle factors and evaluate the forecast performance of the expanded model across all countries and within geographical regions. Finally, we discuss country specific details.

\subsection{Forecasting GDP using one global component}

Figures $2 \mathrm{a}$ and $2 \mathrm{~b}$ report the relative out-of-sample forecasting performance for GDP growth in all countries based on root mean square prediction error (RMSPE) and the continuous rank predictability score (CRPS), respectively, at horizons 1 - 5. In each plot the lines are the average relative forecast performance across all 33 countries in the sample. Particularly, for RMSPE and CRPS comparisons, the plots show the cumulative squared prediction errors of the benchmark, minus the cumulative squared prediction error of the Alternative model. Hence, for both graphs, an increase in a 
line indicates better performance of the global model; a decrease in a line indicates better performance of the $\mathrm{AR}(1)$. When the line is above zero the Alternative model has the best average forecast performance up to that point in time. In the plots we also report, with light grey bars, specific episodes that in the literature are considered as important events that might have significant effects on business cycles around the world. These are: ERM; European Exchange Rate Mechanism crisis in 1992, LTCM; Long-Term Capital Management collapse in 1998-1999, NASDAQ; the Nasdaq crash in 1999-2000, US bankruptcies; wave of bankruptcies in the US in 2002, the Financial Crisis; the Global Recession spreading around the world in 2008, see Imbs (2010) for details.

Figure 2 has two main messages: The Great Recession was the first truly global recession in decades, and this time is different. In particular, Figure 2 a shows that at the short term horizons (horizon 1 and 2), a model including one global factor improves forecast performance (i.e., an increase in the line) relative to the benchmark. For RMSPE evaluation, the results are in particular strong when we include the period of the financial crisis, as seen by the sharp increase in the line early in the financial crisis. $^{8}$ Although forecast performance increases steadily from the late 1990s (the Asian crisis), no other major business cycle event, e.g., the LTCM or the NASDAQ crash, caused such abrupt changes in relative forecast performance. Hence, the one- and twosteps ahead forecast performance are greatly improved using information contained in the global business cycle factor. The fact that the forecast performance of the global model increases sharply early in the financial crisis is consistent with the interpretation that the financial crisis is due to a common global shock, which may have affected most economies in a similar way. Using a forecasting framework we therefore confirm what Imbs (2010) has shown in an in-sample business cycle setting: The Great Recession was the first truly global recession in decades. Likewise, the out-of-sample predictive results also confirm the in-sample evidence reported in Figure 1, namely that business cycle synchronization increased during this period. ${ }^{9}$ It is also interesting to note that the short-term forecasting performance of the Alternative model relative to the benchmark declines again in the recovery phase of the financial crisis. Again, this is consistent with the in-sample synchronization results reported in Figure 1, but it is a new finding relative to that reported in Imbs (2010), where the sample ended in 2009:M5.

Using density forecast evaluation, see Figure $2 \mathrm{~b}$, yields consistent results compared to those discussed above. For the short term horizons, the global factor model's forecast performance relative to the benchmark increases almost monotonically already from the start of the evaluation sample. Thus, the Alternative model is better able than the benchmark to correctly capture the whole forecast distribution. If the forecast

\footnotetext{
${ }^{8}$ Our methodology could be extended to forecasting turning points, see, e.g., Chauvet and Piger (2008), Hamilton (2011) and Chauvet and Potter (2013) for analysis related to GDP. We leave it for further research to explore such extensions.

${ }^{9}$ Engel and Wang (2011) has shown that trade in durable goods is an important element in openeconomy rational expectations (RE) macro models that can account for some of the high correlation of output across countries. Yet, and as pointed out by the same authors, the channels explored may be different from those in the traditional RE models. One possibility is that agents receive strong signals about the future common component. If news helps to drive business cycles (c.f., Beaudry and Portier (2007)), then perhaps news about the common component also effectively filters an otherwise noisy signal, thereby increasing forecast performance across countries.
} 
(a) RMSPE

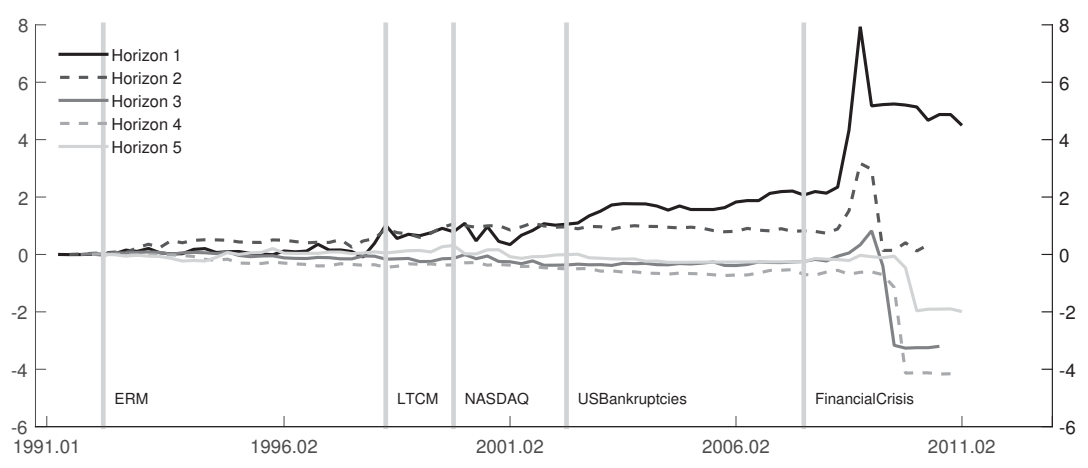

(b) CRPS

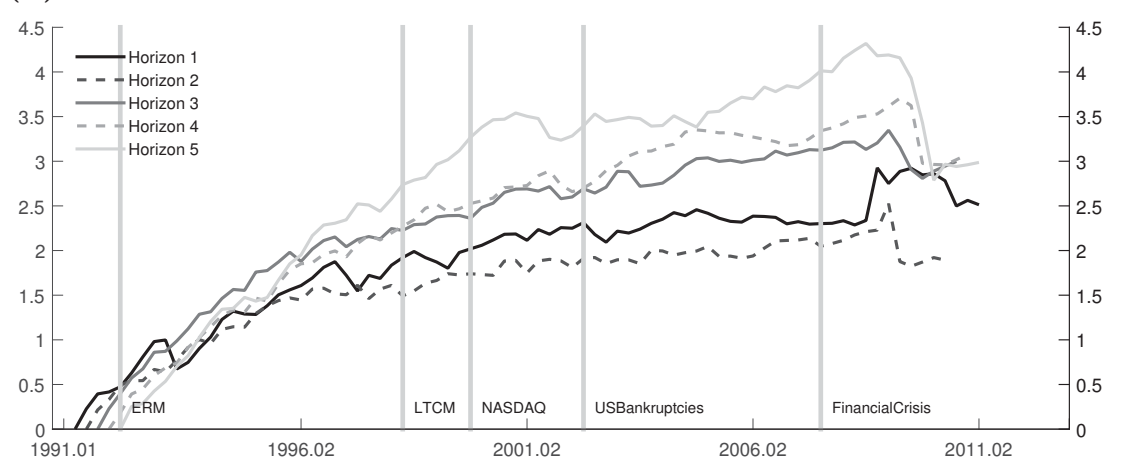

Figure 2. Relative historical forecast performance GDP - one global component. Figures 2a and 2b report relative out-of-sample forecasting performance, measured by the median across all countries. In particular, for RMSPE (CRPS) comparisons the plots show the cumulative squared prediction errors (the CRPS) of the benchmark minus the cumulative squared prediction error (the CRPS) of the Alternative model. An increase in a line indicates better performance of the Alternative model; a decrease in a line indicates better performance of the benchmark. The vertical grey lines identify episodes commonly believed to have global effects, see, e.g., Imbs (2010).

user is more concerned about higher order moments, this is important information and should, all else equal, favour the global factor model. Yet, the increase in the performance of the global factor model relative to the $\mathrm{AR}(1)$ early in the financial crisis stands out.

Turning to the longer forecasting horizons 3 - 5, the forecast performance of the global model and the AR(1) are basically identical, or increase monotonically, throughout most of the evaluation sample when RMSPE and CRPS scores are used, respectively. A few years into the financial crisis, however, the longer forecast horizons deteriorate sharply, in particular for the 5-steps ahead predictions. That is, from $2009 / 2010$, the forecast performance of the global model declines sharply relatively to the benchmark model. This holds for both the RMSPE and the CRPS criteria. Hence, this time is different; Only after the Great Recession do we observe a sharp deterioration of the long horizon forecast performance of the global factor model relative to the benchmark.

The first row of Table 1 reports the results for the PIT tests, summarized as averages across all countries. The null hypothesis of correct calibration, i.e., that the empirical predictive distribution matches the true, unobserved distribution that generates the data, can not be rejected in only 15 (12) percent of the cases for the benchmark model on horizon 1 (horizon 5). For the Alternative model, i.e., the factor 
Table 1. Density calibration statistics: PIT test - one global component. Each table entry shows the fraction of density forecasts passing the Berkowitz (2001) test for zero mean, unit variance and independence of the PITS. The null of the test is no calibration failure, and we have used the 5 percent significance level as a cut-off in computing the fractions in the table. Table 4, in Appendix A, reports the p-values for each individual country. Evaluation sample: 1991:Q1-2011:Q2. We report results for horizon 1 and 5. Results for horizons 2-4 are available at request.

\begin{tabular}{lccccc}
\hline & \multicolumn{2}{c}{ 1-step horizon } & & \multicolumn{2}{c}{ 5-step horizon } \\
\cline { 2 - 3 } \cline { 5 - 6 } & Benchmark & Alternative & & Benchmark & Alternative \\
\hline All & 0.15 & 0.30 & 0.12 & 0.33 \\
North America & 0.00 & 0.67 & & 0.00 & 1.00 \\
Asia & 0.23 & 0.00 & & 0.23 & 0.08 \\
Europe & 0.17 & 0.58 & & 0.08 & 0.50 \\
South America & 0.00 & 0.20 & & 0.00 & 0.20 \\
\hline
\end{tabular}

model, the performance is better, and we can not reject the null hypothesis of correct calibration for 30 (33) percent of the cases on horizon 1 (horizon 5). Thus, the AR(1) model delivers less calibrated predictive densities on average. We notice, although do not tabulate, that the variance of the predictive densities from the DFM is on average smaller than the ones from the AR(1) models. The information content in the common global component seem to reduce the forecast errors, shrink the densities and increase calibration.

In summary, the results reported here emphasize two regularities: First, while the global factor model on average outperforms the simple benchmark model using both RMSPE and CRPS scoring rules, the factor model seems to be particularly good (relative to the benchmark) at correctly capturing the whole forecast distribution, i.e., when using the CRPS scoring rule. Second, in line with in-sample evidence showing an increase in cross-country business cycle synchronization during the Great Recession, we find a large and positive increase in the short-term relative forecasting performance of the global factor model during this period. However, our results indicate that this time is different; during the recovery phase of the recession relative forecasting performance declines, especially at longer forecasting horizons. What can explain this pattern? One explanation can simply be regionalism, which we address in the next section.

\subsection{Forecasting GDP including regional components}

Newer studies in the business cycle synchronization literature highlight a growing importance of regional business cycle developments relative to global ones, see, e.g., Crucini et al. (2011), Mumtaz et al. (2011) and Thorsrud (2013). In line with this, we see from the decompositions in Table 1 that there are large regional differences in forecasting performance when a model including only one common global factor is used for prediction. In particular, the density forecasts for Asia are badly calibrated, i.e., they do not pass the test. In fact, the benchmark model, does a better job with 23 percent of the countries passing the test (both horizons). This suggests a weak forecast performance when using the global model for many Asian countries. ${ }^{10}$ The evidence

\footnotetext{
${ }^{10} \overline{\text { However, for the majority of countries }}$ in North America and Europe, we cannot reject the null hypothesis of no calibration failure. Moreover, the Alternative model outperforms the benchmark by a large margin. This also holds for countries in South America on average, but the fraction of
} 
provided in newer business cycle synchronization studies, and the decomposition results in Table 1, therefore naturally beg the question: Can we improve the relative forecasting performance of the factor model by including region specific business cycle factors? To address this question we re-specify the global factor model such that it includes four regional business cycle factors: A North American factor, an Asian factor, a European factor, and a South American factor. The four factors are identified by employing the following ordering of the first four variables in $y_{t}$ : the US, Korea, Germany, Brazil. Thus, with reference to the factor identification scheme described in Section 2, the $\lambda_{0,1}$ matrix is an identity matrix. We note that other alternative factor identification schemes could have been employed, see, e.g., Bai and Wang (2015). We prefer the one selected because it leaves the $\operatorname{VAR}(h)$ dynamics completely unrestricted and allows for contemporaneous spillovers between the regional factors. ${ }^{11}$ Accounting for such spillovers is consistent with findings in, e.g., Thorsrud (2013).

The four factors, as estimated using the whole sample, are reported in Figure 8 in Appendix A. We note six silent facts: First, the North American factor resembles the one global factor used in Section 3.1. Second, the Great Recession is visible in all four factor estimates. Third, the Asian crisis around 1998 is clearly visible in the Asia-specific business cycle factor and not in any of the other estimates. Fourth, the European business cycle factor resembles the North American business cycle factor, questioning the presence of any truly common European specific business cycle factor, see, e.g., Canova et al. (2007). Fifth, the South American business cycle shows large and volatile swings in the early part of the sample, consistent with the period when many of the South American countries were fighting hyper-inflation and particularly unstable macroeconomic developments. Finally, both the Asian and the South American factor experience a much quicker recovery after the financial crisis than what is observed in the US and European factors.

The results of the new out-of-sample forecasting experiment with the factor model including four regional factors as the Alternative model, are reported in Figures 3a and 3b, for RMSPE and CRPS scores, respectively. As in Figure 2, we here only report averages across all countries. The effect of the Great Recession dominates both the short-run and long-run relative forecast performance. However, the absolute forecasting performance, relative to the benchmark, seems to become somewhat better after including the additional factors, at least for RMSPE evaluation. That is, the distance from the zero line is larger (smaller, when negative) than in Figures $2 \mathrm{a}$ and 2b. Moreover, almost irrespective of forecast horizon, the performance does not seem to deteriorate as much at the end of the evaluation sample.

Detailed results for all the four regions are reported in Figures 9 and 10 in Appendix A. For the countries in North America and in Europe we confirm the absolute forecasting performance, relative to the AR(1). Also for South America, we observe that for RMSPE evaluation the absolute relative performance increases over the sample, both for short-run and long-run forecasting. The performance of the augmented model relative to the AR(1) detoriates less than for the US and Europe at the end, in particular for the long-run forecasting. Moreover, the effect of the Great Recession on relative forecasting performance is not visible. For Asia, the relative short-run point

countries in the region actually passing the test is only 20 percent.

${ }^{11}$ That is, under standard identification schemes the errors in (2) must be uncorrelated. Under the identification scheme used here, no such restriction is needed. 
(a) RMSPE

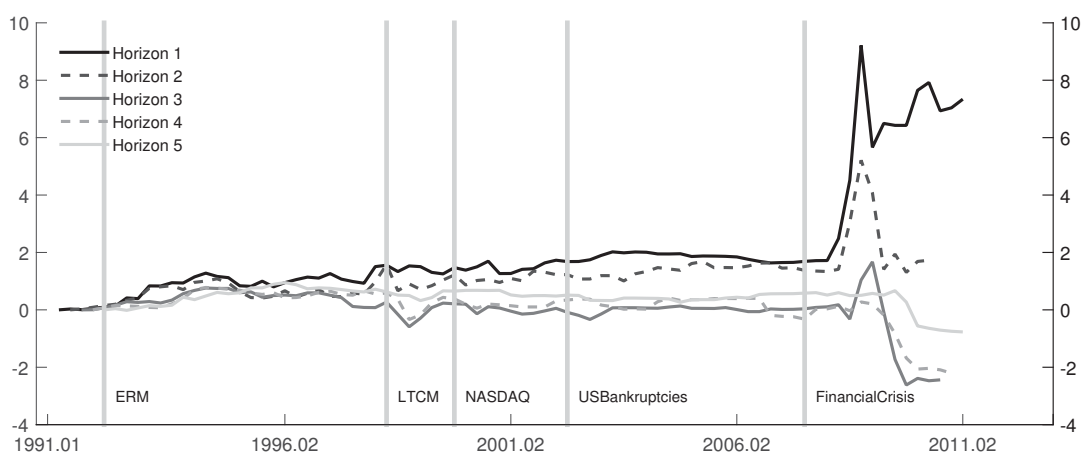

(b) CRPS

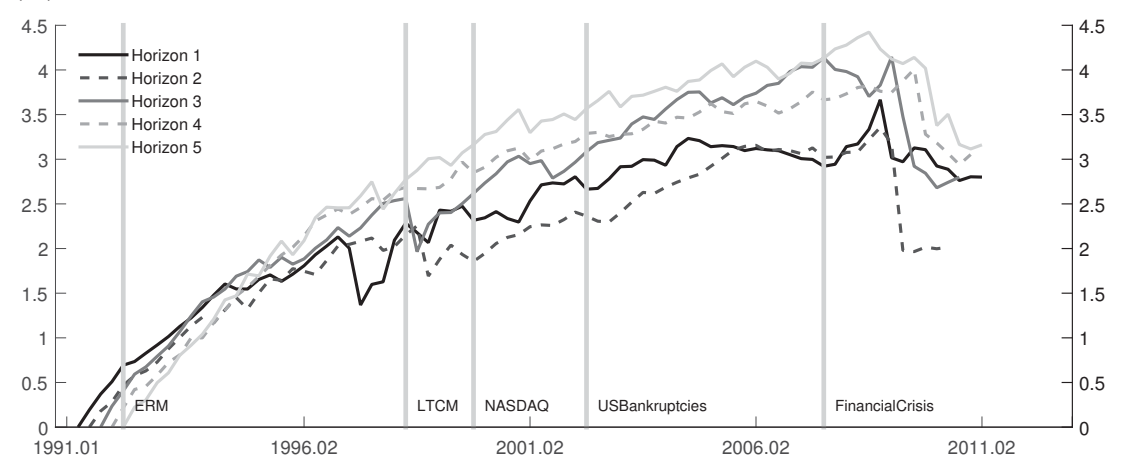

Figure 3. Relative historical forecast performance GDP - four regional components. See also the notes to Figure 2.

forecasting performance of the augmented model improves over the sample. Especially, the effects of the Asian crisis are evident, resulting in a large and lasting increase in relative forecasting performance. The same dramatic shift can be seen when looking at Figure 10 and CRPS evaluation. Thus, including an Asia-specific business cycle factor improves forecasting performance for the Asian countries over the sample.

Table 2 reports the PIT tests for the factor model with four factors and the AR(1). Comparing the results in Table 2 to those in Table 1, we see that augmenting the factor model with four regional factors clearly improves the calibration of the density forecast, although not uniformly. On average across all countries 42 (36) percent now pass the test on horizon 1 (horizon 5). Most of the gain comes through a better calibration obtained for countries in Asia in particular, but also to some extent for countries in South America. Thus, our experiment suggests that the relative forecasting performance seems to improve and also yield better calibrated densities for most countries when regional factors are accounted for.

In sum, regional factors matter, at least for short-term forecasting. Augmenting the one-factor model to include up to four regional business cycle factors yields an improvement in relative scores and gives better calibrated density forecasts. This result is consistent with business cycle synchronization studies documenting an increase in the importance of regional factors (relative to one global business cycle factor), but was not shown to hold in an out-of-sample forecasting experiment. As such, our results offer an important extension to the existing in-sample business cycle synchronization literature. The results should also be of interest to model builders, policy makers and forecasters searching for which variables to include in their forecasting framework: Incorporating 
Table 2. Density calibration statistics: PIT test - four regional components. See also the notes to Table 1.

\begin{tabular}{|c|c|c|c|c|}
\hline & \multicolumn{2}{|c|}{ 1-step horizon } & \multicolumn{2}{|c|}{ 5-step horizon } \\
\hline & Benchmark & Alternative & Benchmark & Alternative \\
\hline All & 0.15 & 0.42 & 0.12 & 0.36 \\
\hline North America & 0.00 & 0.67 & 0.00 & 0.67 \\
\hline Asia & 0.23 & 0.15 & 0.23 & 0.15 \\
\hline Europe & 0.17 & 0.67 & 0.08 & 0.58 \\
\hline South America & 0.00 & 0.40 & 0.00 & 0.20 \\
\hline
\end{tabular}

common global and regional factors might increase forecasting accuracy. ${ }^{12}$

Still, the two marked characteristics in Figure 3, as in Figure 2, are the dramatic increase in relative forecasting performance during the financial crisis, and the subsequent drop in relative forecasting performance during the recovery phase of the Great Recession. We turn to this issue below.

\subsection{Country specific details and alternative groupings}

The average results across all countries or regions discussed so far can easily hide interesting patterns. In this section we examine the country specific details behind Figure 3 , as well as tests of significance in terms of difference in forecasting performance. ${ }^{13}$ Thereafter we investigate further if alternative categorizations of the countries can help in understanding the defining characteristics of the results presented in Figure 3.

To organise the discussion for the individual countries, we focus on performance up until the financial crisis, and then on the period thereafter, see Figures 4 and 5 for horizons 1 and 5, respectively. On average, the short-term forecasting performance of the Alternative model increases before and immediately after the Great Recession. Focusing on the period up until 2007:Q3, we see that for many of the individual countries the performance of the Alternative model is also significantly better than the benchmark. This is especially so for CRPS evaluation. Among the countries where the factor model does not seem to add much value in terms of short-term forecasting are New Zealand, Turkey, Thailand, Saudi Arabia, Philippines, Peru, Japan, Indonesia, India, China, Brazil, Australia and Norway (although only in the period preceding the financial crisis), see Figures $4 \mathrm{a}$ and $4 \mathrm{~b}$. Interestingly, these are either emerging or commodity exporting countries. From Table 3 in Appendix A we observe that these countries are very different from the other countries in that they have exceptionally high and (or) volatile growth rates. As the factor model captures commonalities across

${ }^{12}$ As a robustness, we report in Table 5, in Appendix A, point forecast evaluations against another often used benchmark model, the Random Walk. The improvements in relative scores are on average larger, and more often significantly so, than when the simple autoregressive benchmark is used. To address the inherent uncertainty regarding how many regional business cycle factors to include in the model, we have also run an experiment incorporating model uncertainty using forecast combination techniques. The results from this experiment can be obtained on request, but suggests that a four factor model is preferred to models including fewer regional factors. Moreover, combining the forecasts from factor models including one to four factors increases relative forecast performance further.

${ }^{13}$ For the country specific results we use the regional model as the Alternative model, as the average forecast performance increased slightly using the regional model over the global model. 
(a) 1990:Q1-2007:Q3

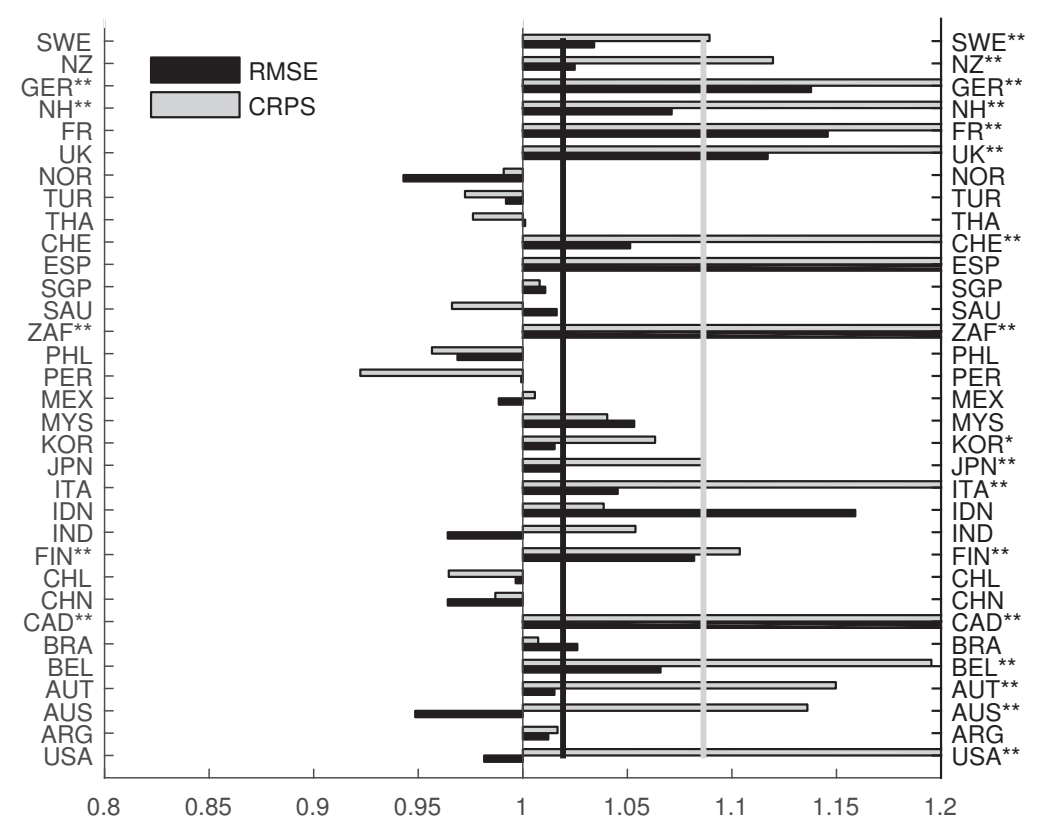

(b) 2007:Q4-2011:Q2

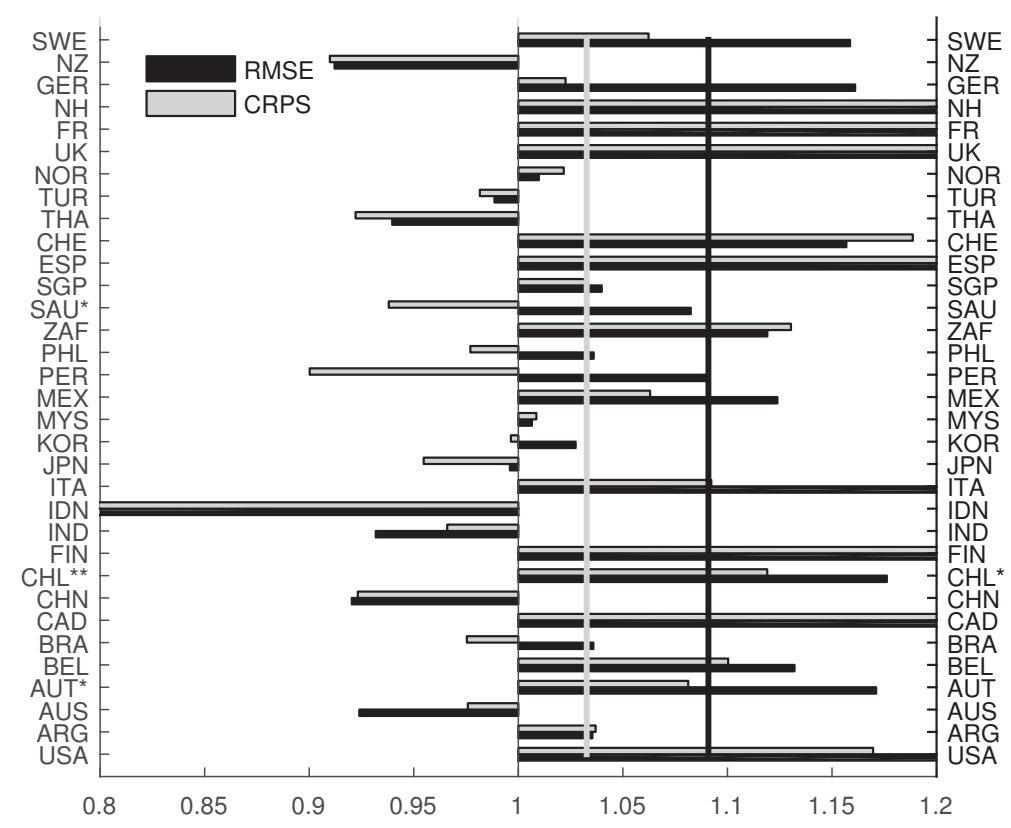

Figure 4. Relative historical forecast performance GDP - four regional components, horizon 1. The bars show the relative forecast performance of the Alternative models against the benchmark, normalized such that a value larger than 1 indicates that the Alternative model is better. The vertical lines report the average relative score across all countries. The left- (right-) hand side y-axis reports the variable names together with Diebold and Mariano (1995) $t$-tests for equality of the RMSPE (CRPS). Based on one-sided tests a rejection of the null of equal accuracy versus the alternative that the Alternative model is superior to the benchmark is shown by one or two asterisks, corresponding to significance levels of $10 \%$ and $5 \%$, respectively. Country abbreviations are listed in Table 3 , in Appendix A.

countries, it is not surprising that it does not add value in terms of forecasting per- 
(a) 1990:Q1-2007:Q3

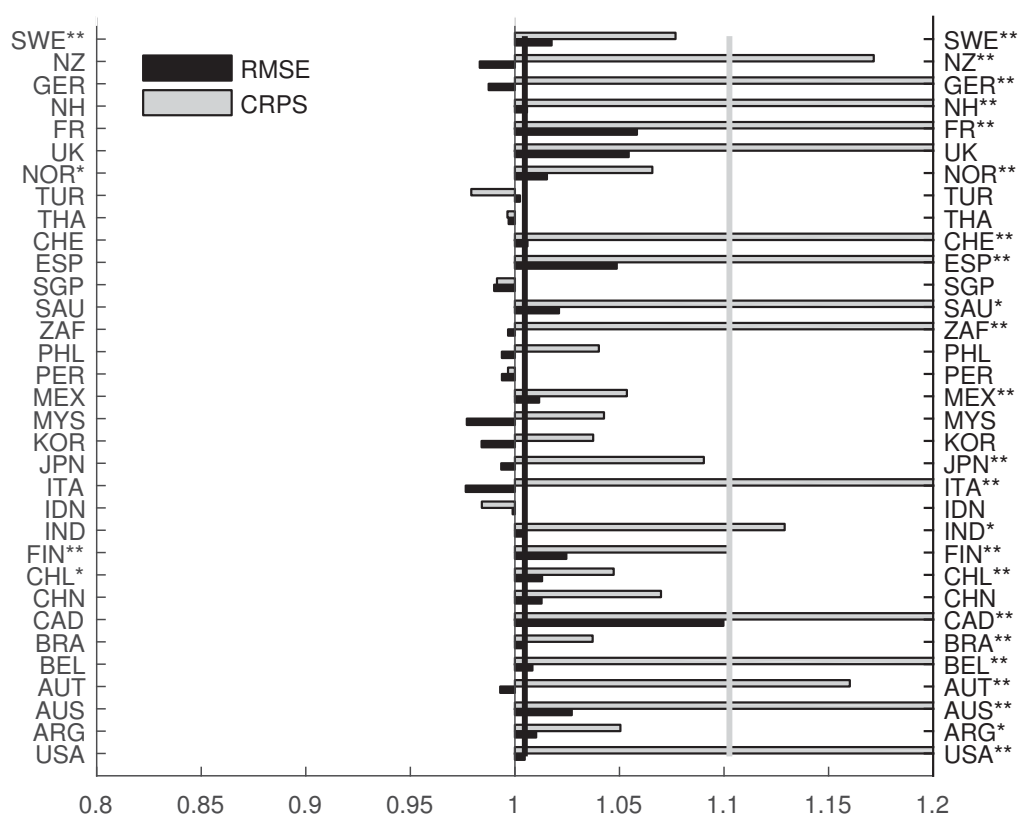

(b) 2007:Q4-2011:Q2

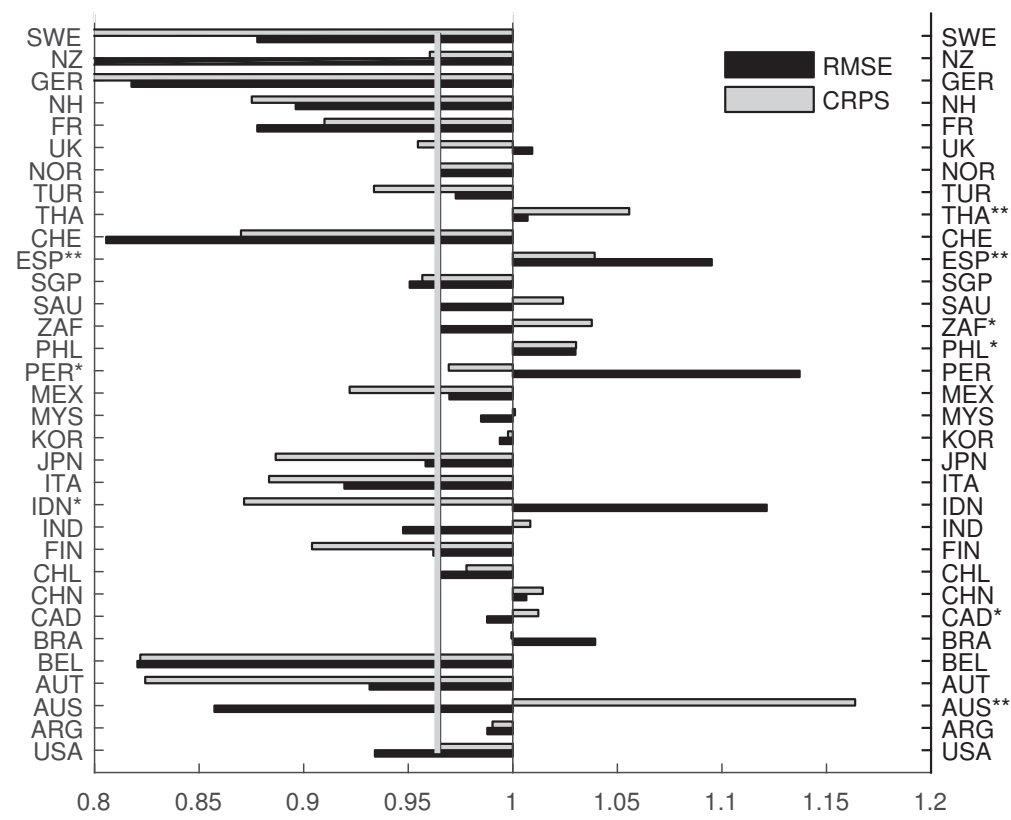

Figure 5. Relative historical forecast performance GDP - four regional components, horizon 5. See also the notes to Figure 4.

formance for these countries. Turning to longer-term forecasting, almost all countries benefit from entertaining the Alternative model, but as emphasized above, more so for density forecasting than for point forecasting, see Figure 5a. Going into the crisis, however, the picture is reversed, and now most of the countries do worse when entertaining the factor model relative to the benchmark. Exceptions are again many of the same countries that stood out at the shorter forecasting horizon, although now the regional factors add value in terms of forecast accuracy. Why is this? Recall 
Emerging countries
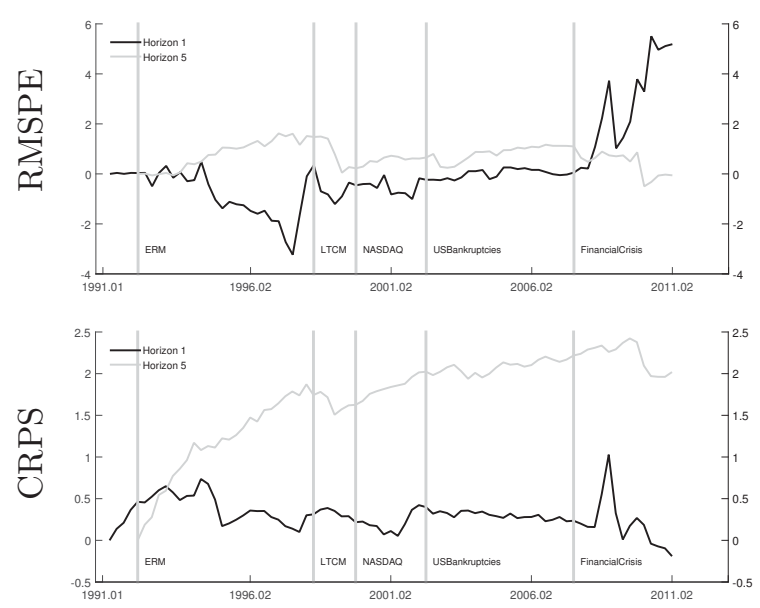

Developed countries
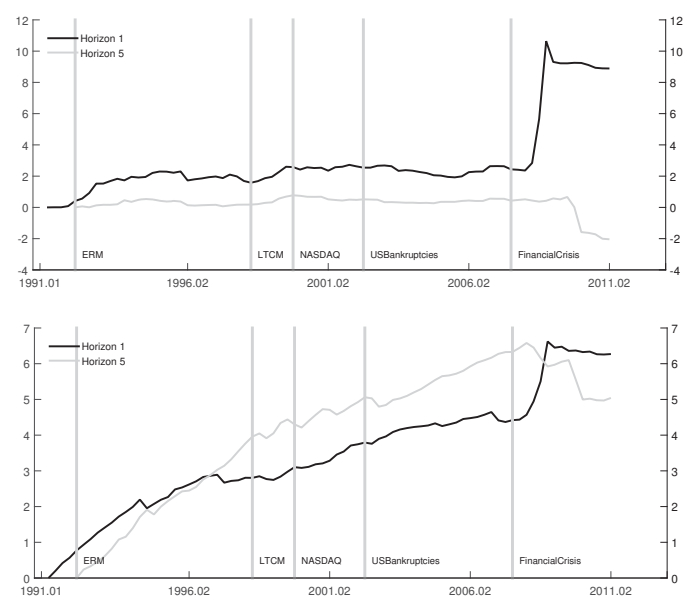

Figure 6. Relative historical forecast performance GDP - emerging (plus commodity exporting) countries versus developed countries. See also the notes to Figure 2.

from Figure 8 and the discussion above, that both the Asian and the South American factor experience a much quicker recovery and subsequently higher growth rates after the financial crisis than the US and European factors. Hence, one suggestion could be that by including regional factors we have increased forecast accuracy among many emerging countries in Asia and South America after the financial crisis.

To explore the difference in predictive scores between the countries further, we finally report in Figure 6 the relative out-of-sample forecasting performance, again based on RMSPE and CRPS, when the predictive scores for each country are grouped into emerging (plus commodity exporters) ${ }^{14}$ and developed countries. The picture confirms what we saw above, and holds both for the point and the density forecasts. It is the developed countries that benefited the most from entertaining the Alternative model going into the financial crisis. Although the short term forecast performance of the emerging and commodity exporters also increase, the gain is less than for the developed countries (compare the scale for the one-step ahead forecasts in the left and right graphs). Similarly, we see that going out of the recession, the relative long term forecast performance (horizon 5) falls by much more for the developed countries than for the emerging and commodity exporting countries. Hence, it seems the factor model adds the most value to the developed countries going into the global recession, while in the recovery phase, the economic developments in these countries have been more dispersed. One interpretation of these results, and to the extent that forecast errors are a good proxy for uncertainty, is offered by Baker et al. (2013). They find that since 2008/2009 uncertainty about the US fiscal situation and economic policies in Europe, in particular, has surged and slowed down the pace of an already slow recovery in these countries and areas. These idiosyncratic developments favour the benchmark model relative to the model entertaining common global business cycle components.

In trying to understand the defining characteristics of the results presented earlier we have also experimented with grouping the predictive scores for each country using

\footnotetext{
${ }^{14}$ We group emerging countries together with commodity exporters based on the observations in Figures 4 and 5. Such a grouping is also consistent with recent findings in the literature which finds that demand from fast growing emerging countries has pushed up commodity prices, and thereby benefited commodity exporters in particular, see e.g. Aastveit et al. (2015).
} 
other categorizations; Large versus small countries, inflation targeting central bank versus not, and high versus low debt. Neither of these alternative groupings provide additional understanding of why the recovery phase following the Great Recession has been so dispersed when it comes to out-of-sample forecasting precision using common factors.

Going forward, a natural extension to the experiments conducted here, and also to those conducted in in-sample based business cycle synchronization studies, is to investigate whether or not other factor structures than those based on geographical belonging can capture important business cycle co-movement. Exploiting common factors can provide model builders and forecasters with more parsimonious model structures, and, as shown here, add marginal predictive power for density forecasting in particular.

\section{Conclusion}

The in-sample evidence pointing toward a high degree of co-movement in aggregate GDP across a large number of countries is well documented in the business cycle literature. However, high co-movement in-sample does not necessarily imply good out-of-sample performance, and inference without out-of-sample verification is likely to be spurious, with an out-of-sample approach inherently involving less over-fitting. In light of findings in, e.g., Imbs (2010), that argue that the Great Recession was the first really global recession in decades, understanding the nature of predictability using common global components seems especially relevant.

This paper therefore asks: Does a model with common international business cycle factors add marginal predictive power relative to a purely domestic alternative, i.e., a simple autoregressive process? To answer this question we employ a Dynamic Factor Model, commonly used in the business cycle synchronization literature, and run an outof-sample forecasting experiment. We forecast GDP growth for a total of 33 countries and evaluate the forecast performance across 82 out-of-sample periods using both point and density evaluation measures.

Our results show that exploiting the informational content in a common global business cycle factor add marginal predictive power: It improves forecasting accuracy in terms of both point and density forecast evaluation across a large panel of countries. In line with in-sample evidence, we also document that the Great Recession has a huge impact on this result. Irrespective of which loss function we use, the event causes a clear preference shift towards the model including a common global factor. Similar shifts are not observed earlier in the evaluation sample. However, this time is different also in other respects. On longer forecasting horizons the performance of the DFM deteriorates substantially in the aftermath of the Great Recession. This indicates that the recession shock itself was felt globally, but that the recovery phase has been very different across countries. Augmenting the DFM with regional factors improves the performance of the model further, giving out-of-sample support to the in-sample studies advocating the importance of regional business cycle factors, but does not fully alleviate the relative deterioration of marginal predictive power observed after the Great Recession period. 


\section{References}

Aastveit, K. A., H. C. Bjørnland, and L. A. Thorsrud (2015). What drives oil prices? Emerging versus developed economies. Journal of Applied Econometrics 30(7), 1013-1028.

Alessi, L., E. Ghysels, L. Onorante, R. Peach, and S. Potter (2014). Central bank macroeconomic forecasting during the global financial crisis: the european central bank and federal reserve bank of new york experiences. Journal of Business 86 Economic Statistics 32(4), 483-500.

Ambler, S., E. Cardia, and C. Zimmermann (2002). International transmission of the business cycle in a multi-sector model. European Economic Review 46(2), 273 300 .

Andrews, D. and J. . Monahan (1992). An improved heteroskedasticity and autocorrelation consistent covariance matrix estimator. Econometrica 60, 953-966.

Ashley, R., C. W. J. Granger, and R. Schmalensee (1980). Advertising and aggregate consumption: An analysis of causality. Econometrica 48(5), 1149-1167.

Backus, D., P. J. Kehoe, and F. E. Kydland (1995). International business cycles: Theory and evidence. In C. Plosser (Ed.), Frontiers of Business Cycle Research, pp. 331-257. Princeton University Press.

Backus, D. K. and P. J. Kehoe (1992). International evidence of the historical properties of business cycles. American Economic Review 82(4), 864-88.

Bai, J. and S. Ng (2013). Principal components estimation and identification of static factors. Journal of Econometrics 176, 18-29.

Bai, J. and P. Wang (2015). Identification and bayesian estimation of dynamic factor models. Journal of Business \&5 Economic Statistics 33(2), 221-240.

Baker, S. R., N. Bloom, and S. J. Davis (2013). Measuring economic policy uncertainty. Chicago Booth research paper 13-02.

Baxter, M. and M. A. Kouparitsas (2005). Determinants of business cycle comovement: A robust analysis. Journal of Monetary Economics 52(1), 113-157.

Beaudry, P. and F. Portier (2007). When can changes in expectations cause business cycle fluctuations in neo-classical settings? Journal of Economic Theory 135(1), 458-477.

Berkowitz, J. (2001). Testing Density Forecasts, with Applications to Risk Management. Journal of Business \& Economic Statistics 19(4), 465-74.

Bjørnland, H. C. and L. A. Thorsrud (2015). Boom or gloom? Examining the Dutch disease in two-speed economies. Economic Journal (forthcoming).

Canova, F., M. Ciccarelli, and E. Ortega (2007). Similarities and convergence in G-7 cycles. Journal of Monetary Economics 54(3), 850-878. 
Carter, C. K. and R. Kohn (1994). On gibbs sampling for state space models. Biometrika $81(3)$, pp. 541-553.

Chauvet, M. and J. Piger (2008). Comparison of the real-time performance of business cycle dating methods. Journal of Business and Economic Statistics 26, 42-49.

Chauvet, M. and S. Potter (2013). Forecasting output. Handbook of Economic Forecasting 2, 141-194.

Clark, T. and M. McCracken (2011). Testing for unconditional predictive ability. In O. Oxford University Press (Ed.), Oxford Handbook of Economic Forecasting. Clements, M.P. and Hendry, D.F.

Clark, T. and M. W. McCracken (2015). Nested forecast model comparisons: a new approach to testing equal accuracy. Journal of Econometrics 186(1), 160-177.

Clark, T. and F. Ravazzolo (2015). The macroeconomic forecasting performance of autoregressive models with alternative specifications of time-varying volatility. Journal of Applied Econometrics 30(4), 551-575.

Crucini, M., A. Kose, and C. Otrok (2011). What are the driving forces of international business cycles? Review of Economic Dynamics 14(1), 156-175.

D'Agostino, A., D. Giannone, and P. Surico (2006). (Un) Predictability and macroeconomic stability. Unpublished manuscript.

Diebold, F. X., T. Gunther, and A. S. Tay (1998). Evaluating Density Forecasts with Applications to Finance and Management. International Economic Review 39, 863-883.

Diebold, F. X. and R. S. Mariano (1995). Comparing predictive accuracy. Journal of Business 86 Economic Statistics 13(3), 253-63.

Engel, C. and J. Wang (2011). International trade in durable goods: Understanding volatility, cyclicality, and elasticities. Journal of International Economics 83(1), $37-52$.

Gneiting, T. and A. E. Raftery (2007). Strictly proper scoring rules, prediction, and estimation. Journal of the American Statistical Association 102, 359-378.

Gneiting, T. and R. Ranjan (2011). Comparing density forecasts using threshold- and quantile-weighted scoring rules. Journal of Business and Economic Stastistics 29, $411-422$.

Groen, J., R. Paap, and F. Ravazzolo (2012). Real-time inflation forecasting in a changing world. Journal of Business and Economic Stastistics 31(1), 29-44.

Hamilton, J. D. (2011). Calling recessions in real time. International Journal of Forecasting 27(4), 1006-1026.

Imbs, J. (2010). The First Global Recession in Decades. IMF Economic Review 58(2), 327-354. Conference on Economic Linkages, Spillovers, and the Financial Crisis, Paris, France, January 28-29, 2010. 
Jurado, K., S. C. Ludvigson, and S. Ng (2015). Measuring uncertainty. American Economic Review 105(3), 1177-1216.

Kim, C.-J. and C. R. Nelson (1999). State-Space Models with Regime Switching: Classical and Gibbs-Sampling Approaches with Applications (1 ed.), Volume 1. The MIT Press.

Kose, M. A., C. Otrok, and C. H. Whiteman (2003). International business cycles: World, region, and country-specific factors. American Economic Review 93(4), 1216-1239.

Lopes, H. and M. West (2004, JAN). Bayesian model assessment in factor analysis. STATISTICA SINICA 14(1), 41-67.

Mitchell, J. and K. F. Wallis (2010). Evaluating Density Forecasts: Forecast Combinations, Model Mixtures, Calibration and Sharpness. Journal of Applied Econometrics 26(6), 1023-1040.

Mumtaz, H., S. Simonelli, and P. Surico (2011). International comovements, business cycle and inflation: A historical perspective. Review of Economic Dynamics 14(1), 176-198.

Negro, M. D. and C. Otrok (2008). Dynamic factor models with time-varying parameters: measuring changes in international business cycles. Staff Reports 326, Federal Reserve Bank of New York.

Ravazzolo, F. and S. Vahey (2013). Forecast densities for economic aggregates from disaggregate ensembles. Studies in Nonlinear Dynamics and Econometrics forthcoming.

Stock, J. H. and M. W. Watson (1999). Forecasting inflation. Journal of Monetary Economics 44(2), 293-335.

Stock, J. H. and M. W. Watson (2002). Macroeconomic forecasting using diffusion indexes. Journal of Business \& Economic Statistics 20(2), 147-62.

Stock, J. H. and M. W. Watson (2005a, July). Implications of dynamic factor models for VAR analysis. NBER Working Papers 11467, National Bureau of Economic Research, Inc.

Stock, J. H. and M. W. Watson (2005b). Understanding changes in international business cycle dynamics. Journal of the European Economic Association 3(5), 9681006 .

Stockton, D. (2012). Review of the monetary policy committee's forecasting capability. Report presented to the Court of the Bank of England, October.

Thorsrud, L. A. (2013). Global and regional business cycles. shocks and propagations. (0012).

Welch, I. and A. Goyal (2008). A Comprehensive Look at the Empirical Performance of Equity Premium prediction. Review of Financial Studies 21(4), 253-303. 


\section{Appendices}

\section{Appendix A Additional figures and tables}

Table 3. Data and factor statistics. Columns 2-4 report the mean, standard deviation (Std.) and autocorrelation (ACF) of the individual series. The ACF statistic is computed as the sum of the autocorrelation coefficients on lag 1-5. The RMSE columns report the root mean squares error associated with variable $i$ in explaining factor $j$. See the notes to Figure 7 for further explanation, but note that the numbers reported here reflect the estimates from a DFM with 4 regional factors, confer Figure 8. The last column, Share, reports the countries average percentage share of world GDP (PPP adjusted) across the period 1980 - 2011 (source: World Economic Outlook, IMF, 2015). In total, the countries in the sample account for roughly 80 percent of world GDP.

\begin{tabular}{|c|c|c|c|c|c|c|c|c|}
\hline \multirow[t]{2}{*}{ Country } & \multicolumn{3}{|c|}{$\begin{array}{l}\text { Statistics } \\
\text { Data }\end{array}$} & \multicolumn{4}{|l|}{$\begin{array}{l}\text { RMSE } \\
\text { Factors }\end{array}$} & \multirow[t]{2}{*}{ Share } \\
\hline & Mean & Std. & $\mathrm{ACF}$ & N. Am. & Asia & Europe & S. Am. & \\
\hline Argentina (ARG) & 0.64 & 2.19 & 1.09 & 0.58 & 1.01 & 0.64 & 0.71 & 0.96 \\
\hline Australia (AUS) & 0.79 & 0.75 & 0.99 & 0.56 & 1.03 & 0.65 & 0.69 & 1.13 \\
\hline Austria (AUT) & 0.54 & 1.13 & 0.64 & 0.57 & 1.03 & 0.63 & 0.72 & 0.53 \\
\hline Belgium (BEL) & 0.49 & 0.70 & 0.67 & 0.56 & 1.02 & 0.60 & 0.69 & 0.66 \\
\hline Brazil (BRA) & 0.70 & 1.77 & 0.05 & 0.57 & 1.03 & 0.64 & 0.70 & 3.53 \\
\hline Canada (CAD) & 0.63 & 0.76 & 0.42 & 0.50 & 1.03 & 0.65 & 0.66 & 1.89 \\
\hline Chile (CHL) & 1.13 & 2.00 & 0.48 & 0.57 & 1.02 & 0.64 & 0.69 & 0.32 \\
\hline China (CHN) & 2.47 & 1.14 & 0.35 & 0.57 & 1.03 & 0.65 & 0.72 & 6.79 \\
\hline Finland (FIN) & 0.59 & 1.39 & 0.41 & 0.56 & 1.03 & 0.65 & 0.71 & 0.30 \\
\hline France (FR) & 0.44 & 0.50 & 0.23 & 0.55 & 1.00 & 0.59 & 0.72 & 3.61 \\
\hline Germany (GER) & 0.42 & 0.88 & -0.10 & 0.56 & 1.03 & 0.58 & 0.70 & 5.27 \\
\hline India (IND) & 1.54 & 0.99 & 1.07 & 0.58 & 1.03 & 0.65 & 0.72 & 4.14 \\
\hline Indonesia (IDN) & 1.24 & 2.17 & 0.77 & 0.57 & 1.01 & 0.64 & 0.70 & 1.94 \\
\hline Italy (ITA) & 0.36 & 0.65 & 0.80 & 0.54 & 1.01 & 0.59 & 0.70 & 3.58 \\
\hline Japan (JPN) & 0.46 & 1.03 & 0.31 & 0.57 & 1.00 & 0.62 & 0.72 & 7.09 \\
\hline Korea (KOR) & 1.45 & 1.65 & -0.03 & 0.56 & 0.82 & 0.62 & 0.71 & 1.32 \\
\hline Malaysia (MYS) & 1.42 & 1.62 & 0.23 & 0.56 & 0.87 & 0.61 & 0.65 & 0.53 \\
\hline Mexico (MEX) & 0.65 & 1.56 & 0.82 & 0.56 & 1.02 & 0.63 & 0.68 & 2.50 \\
\hline Netherlands (NH) & 0.51 & 0.78 & -0.03 & 0.56 & 1.02 & 0.62 & 0.70 & 1.07 \\
\hline New Zealand (NZ) & 0.53 & 0.94 & 1.16 & 0.56 & 1.01 & 0.65 & 0.69 & 0.18 \\
\hline Norway (NOR) & 0.68 & 1.21 & 0.06 & 0.57 & 1.03 & 0.64 & 0.71 & 0.43 \\
\hline Peru (PER) & 0.78 & 3.09 & 0.05 & 0.57 & 1.03 & 0.65 & 0.72 & 0.32 \\
\hline Philippines (PHL) & 0.78 & 1.48 & 2.85 & 0.57 & 1.02 & 0.64 & 0.72 & 0.58 \\
\hline Saudi Arabia (SAU) & 0.53 & 2.13 & 0.14 & 0.57 & 1.02 & 0.64 & 0.71 & 1.40 \\
\hline Singapore (SGP) & 1.64 & 1.90 & 1.17 & 0.57 & 0.98 & 0.63 & 0.69 & 0.29 \\
\hline South Africa (ZAF) & 0.61 & 0.84 & 0.57 & 0.56 & 1.02 & 0.64 & 0.66 & 0.81 \\
\hline Spain (ESP) & 0.58 & 0.55 & -0.33 & 0.55 & 1.03 & 0.59 & 0.73 & 2.02 \\
\hline Sweden (SWE) & 0.54 & 1.32 & 1.84 & 0.56 & 1.03 & 0.64 & 0.71 & 0.57 \\
\hline Switzerland (CHE) & 0.44 & 0.68 & 0.98 & 0.56 & 1.01 & 0.62 & 0.68 & 0.63 \\
\hline Thailand (THA) & 1.32 & 1.62 & 1.03 & 0.56 & 0.86 & 0.62 & 0.70 & 0.89 \\
\hline Turkey (TUR) & 1.02 & 2.68 & -0.01 & 0.57 & 1.03 & 0.64 & 0.71 & 1.32 \\
\hline UK (UK) & 0.47 & 0.70 & 0.26 & 0.50 & 1.00 & 0.64 & 0.72 & 3.25 \\
\hline USA (USA) & 0.63 & 0.75 & 1.15 & 0.52 & 1.03 & 0.64 & 0.68 & 20.61 \\
\hline Median (Sum) & 0.63 & 1.14 & 0.48 & 0.56 & 1.02 & 0.64 & 0.70 & $(80.46)$ \\
\hline
\end{tabular}




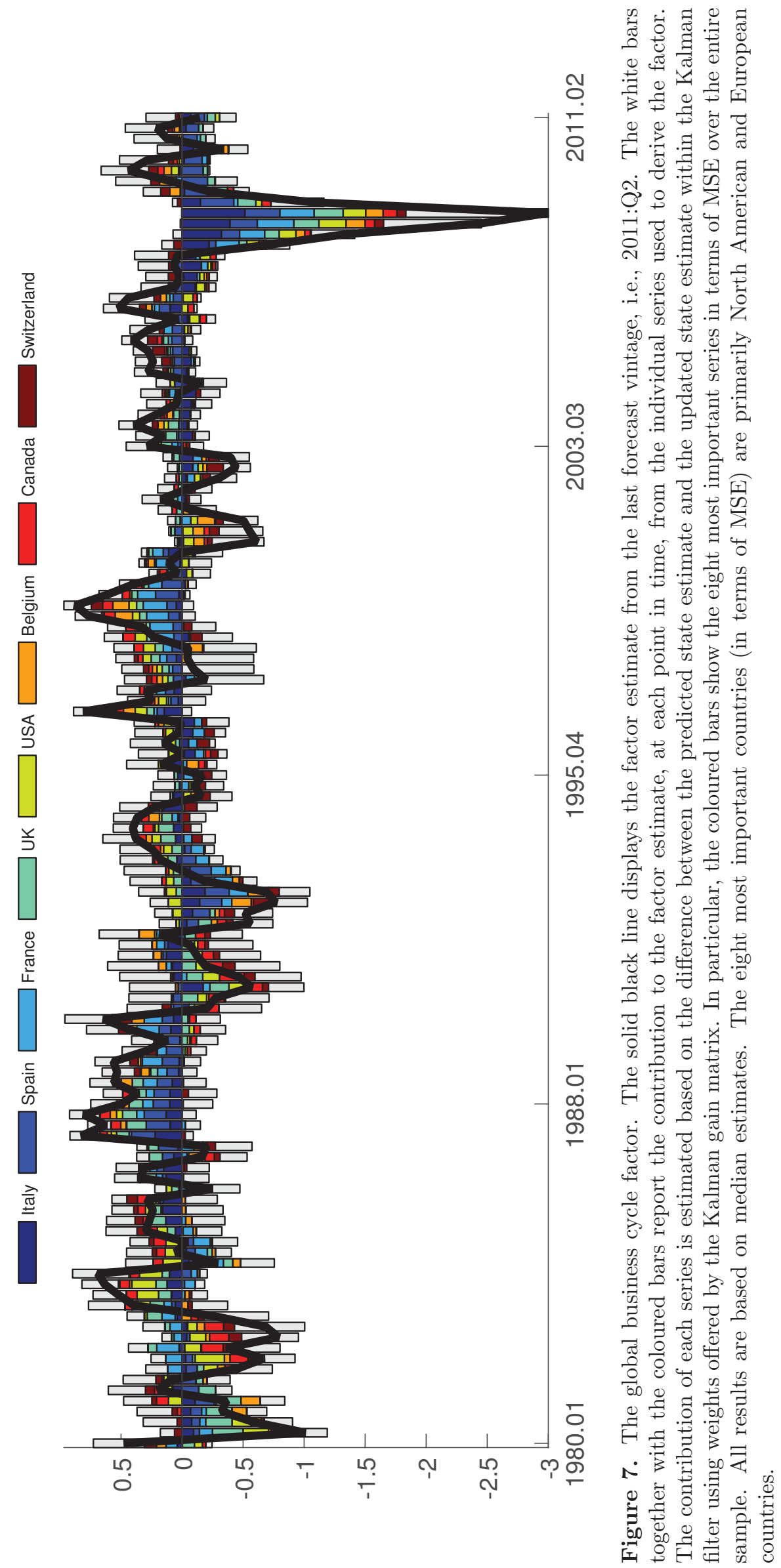


(a) North America

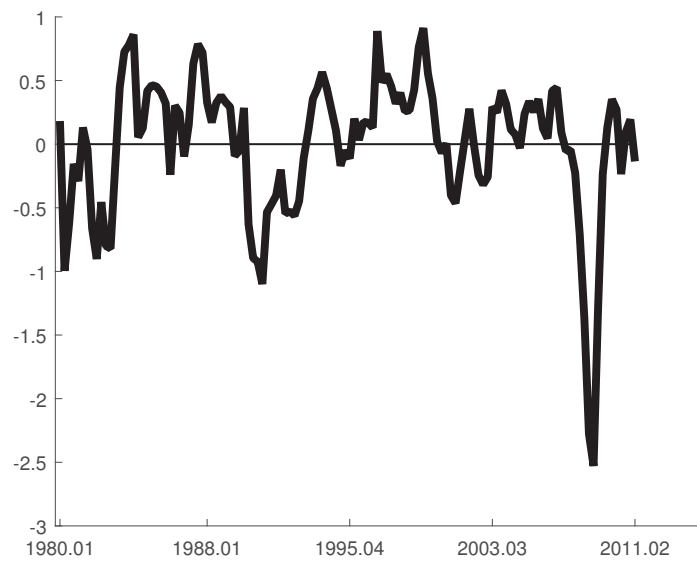

(c) Europe

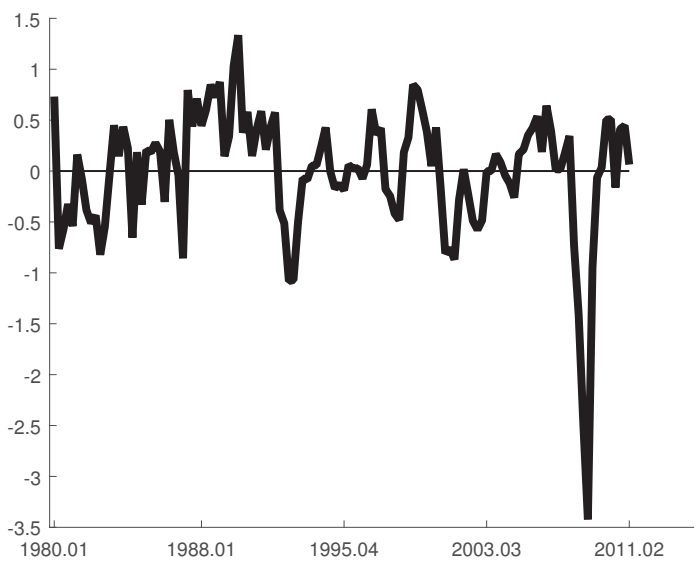

(b) Asia

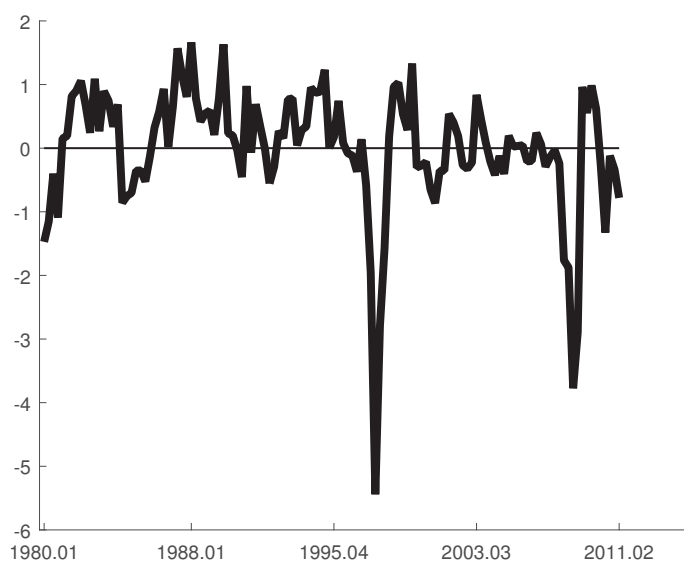

(d) South America

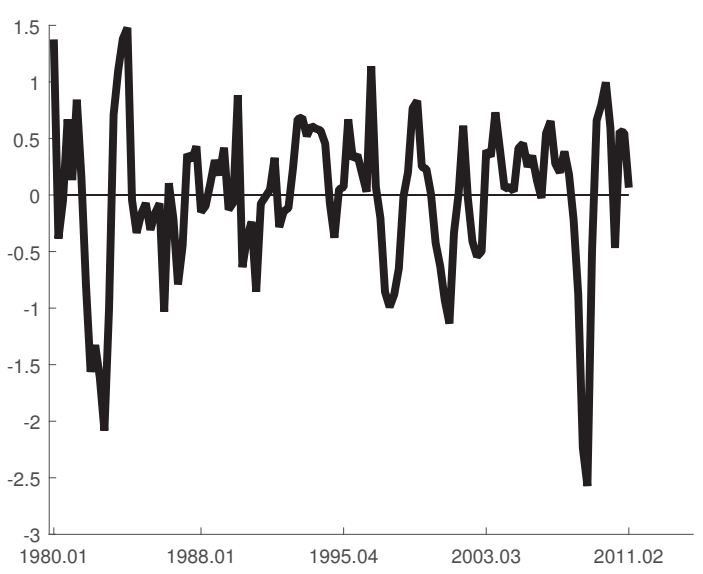

Figure 8. The plots report four regional business cycle factors, estimated using the whole sample and the DFM described in Section 3.2. We note that the global factor estimate reported in Figure 7 has a correlation coefficient of 0.93, 0.49, 0.91, and 0.74 with the North American, Asian, European, and South American regional factor estimates, respectively. 
Table 4. Density calibration statistics: PIT test - one global component, all countries. Each table entry shows the p-value of the Berkowitz (2001) test for zero mean, unit variance and independence of the PITS. The null of the test is no calibration failure. Evaluation sample: 1991:Q1-2011:Q2.

\begin{tabular}{|c|c|c|c|c|}
\hline & \multicolumn{2}{|c|}{ 1-step horizon } & \multicolumn{2}{|c|}{ 5-step horizon } \\
\hline & Benchmark & Alternative & Benchmark & Alternative \\
\hline USA & 0.00 & 0.11 & 0.00 & 0.24 \\
\hline Argentina & 0.02 & 0.38 & 0.00 & 0.00 \\
\hline Australia & 0.00 & 0.00 & 0.00 & 0.01 \\
\hline Austria & 0.67 & 0.86 & 0.03 & 0.00 \\
\hline Belgium & 0.00 & 0.71 & 0.00 & 0.00 \\
\hline Brazil & 0.00 & 0.02 & 0.00 & 0.17 \\
\hline Canada & 0.00 & 0.00 & 0.00 & 0.59 \\
\hline China & 0.02 & 0.00 & 0.00 & 0.00 \\
\hline Chile & 0.00 & 0.00 & 0.00 & 0.00 \\
\hline Finland & 0.14 & 0.66 & 0.23 & 0.31 \\
\hline India & 0.00 & 0.00 & 0.00 & 0.01 \\
\hline Indonesia & 0.00 & 0.00 & 0.08 & 0.52 \\
\hline Italy & 0.00 & 0.00 & 0.00 & 0.00 \\
\hline Japan & 0.00 & 0.00 & 0.00 & 0.00 \\
\hline Korea & 0.00 & 0.02 & 0.00 & 0.02 \\
\hline Malaysia & 0.47 & 0.01 & 0.01 & 0.00 \\
\hline Mexico & 0.01 & 0.13 & 0.00 & 0.15 \\
\hline Peru & 0.00 & 0.00 & 0.00 & 0.00 \\
\hline Philippines & 0.00 & 0.00 & 0.00 & 0.00 \\
\hline South Africa & 0.00 & 0.00 & 0.00 & 0.02 \\
\hline Saudi Arabia & 0.00 & 0.00 & 0.00 & 0.00 \\
\hline Singapore & 0.01 & 0.00 & 0.54 & 0.00 \\
\hline Spain & 0.00 & 0.03 & 0.00 & 0.00 \\
\hline Switzerland & 0.00 & 0.15 & 0.00 & 0.18 \\
\hline Thailand & 0.06 & 0.00 & 0.00 & 0.00 \\
\hline Turkey & 0.53 & 0.03 & 0.41 & 0.02 \\
\hline Norway & 0.00 & 0.06 & 0.00 & 0.09 \\
\hline UK & 0.00 & 0.00 & 0.00 & 0.06 \\
\hline France & 0.00 & 0.55 & 0.00 & 0.00 \\
\hline Netherlands & 0.00 & 0.00 & 0.00 & 0.64 \\
\hline Germany & 0.00 & 0.54 & 0.00 & 0.32 \\
\hline New Zealand & 0.00 & 0.00 & 0.00 & 0.00 \\
\hline Sweden & 0.00 & 0.01 & 0.00 & 0.01 \\
\hline
\end{tabular}


Table 5. Relative historical forecast performance GDP, where the benchmark model is a Random Walk: $y_{t}=y_{t-1}+\epsilon_{t}, y_{t}$ is the growth rate of GDP, and the loss function is RMSPE. The alternative models are the one factor model used in Section 3.1 (Alternative 1), and a model with four regional factors, used in Section 3.2 (Alternative 2). The table entries show the relative forecast performance of the alternative models against the benchmark, normalized such that a value larger than 1 indicates that the alternative is better. Diebold and Mariano (1995) $t$-tests for equality of the RMSPE are reported using one or two asterisks, corresponding to significance, levels of $10 \%$ and $5 \%$, respectively. The tests are based on one-sided tests: a rejection of the null of equal accuracy versus the alternative that the alternative model is superior to the benchmark. Evaluation sample: 1991:Q1-2011:Q2

\begin{tabular}{|c|c|c|c|c|}
\hline & \multicolumn{2}{|l|}{ 1-step horizon } & \multicolumn{2}{|l|}{ 5-step horizon } \\
\hline & Alternative 1 & Alternative 2 & Alternative 1 & Alternative 2 \\
\hline USA & 1.11 & 1.11 & 1.33 & 1.35 \\
\hline Argentina & 1.09 & 1.09 & 1.33 & 1.34 \\
\hline Australia & $1.27^{* *}$ & $1.28^{* *}$ & $1.24^{* *}$ & $1.25^{* *}$ \\
\hline Austria & $1.73^{*}$ & $1.70^{*}$ & $1.40^{*}$ & $1.36^{*}$ \\
\hline Belgium & $1.26^{* *}$ & $1.27^{* *}$ & $1.41^{* *}$ & $1.43^{* *}$ \\
\hline Brazil & $1.33^{* *}$ & $1.36^{* *}$ & $1.47^{* *}$ & $1.49^{* *}$ \\
\hline Canada & 1.17 & $1.25^{* *}$ & 1.39 & $1.52^{*}$ \\
\hline China & $1.20^{* *}$ & $1.22^{* *}$ & $1.24^{* *}$ & $1.24^{* *}$ \\
\hline Chile & $1.33^{* *}$ & $1.31^{* *}$ & $1.38^{* *}$ & $1.41^{* *}$ \\
\hline Finland & $1.35^{* *}$ & $1.41^{* *}$ & $1.43^{* *}$ & $1.47^{* *}$ \\
\hline India & $1.23^{* *}$ & $1.23^{* *}$ & 1.19 & 1.19 \\
\hline Indonesia & 1.03 & 1.16 & $1.36^{*}$ & $1.36^{*}$ \\
\hline Italia & $1.23^{*}$ & $1.23^{*}$ & $1.28^{*}$ & $1.30^{*}$ \\
\hline Japan & 1.15 & 1.16 & $1.34^{*}$ & $1.33^{*}$ \\
\hline Korea & 1.14 & 1.14 & $1.45^{*}$ & $1.43^{*}$ \\
\hline Malaysia & $1.21^{* *}$ & $1.26^{* *}$ & $1.51^{* *}$ & $1.48^{* *}$ \\
\hline Mexico & $1.26^{* *}$ & $1.26^{* *}$ & $1.41^{* *}$ & $1.42^{* *}$ \\
\hline Peru & $1.27^{*}$ & $1.27^{*}$ & $1.37^{* *}$ & $1.40^{* *}$ \\
\hline Philippines & $1.26^{* *}$ & $1.24^{* *}$ & $1.30 * *$ & $1.29^{* *}$ \\
\hline South Africa & 1.03 & 1.00 & $1.26^{*}$ & $1.25^{*}$ \\
\hline Saudi Arabia & $1.09^{* *}$ & $1.09^{*}$ & $1.49 * *$ & $1.52^{* *}$ \\
\hline Singapore & $1.27^{*}$ & $1.31^{*}$ & $1.42^{* *}$ & $1.41^{* *}$ \\
\hline Spain & 0.99 & 1.06 & $1.19^{* *}$ & $1.24^{* *}$ \\
\hline Switzerland & $1.18^{* *}$ & $1.17^{*}$ & $1.40^{* *}$ & $1.41^{* *}$ \\
\hline Thailand & 1.10 & 1.10 & 1.26 & 1.26 \\
\hline Turkey & $1.35^{* *}$ & $1.34^{* *}$ & $1.43^{* *}$ & $1.43^{* *}$ \\
\hline Norway & $1.55^{* *}$ & $1.45^{* *}$ & $1.30^{* *}$ & $1.31^{* *}$ \\
\hline UK & 1.00 & 1.05 & 1.27 & 1.34 \\
\hline France & $1.15^{* *}$ & $1.20^{* *}$ & $1.28^{* *}$ & $1.31^{* *}$ \\
\hline Netherlands & $1.18^{* *}$ & $1.20^{* *}$ & $1.35^{* *}$ & $1.35^{* *}$ \\
\hline Germany & $1.36^{* *}$ & $1.32^{* *}$ & $1.42^{* *}$ & $1.35^{* *}$ \\
\hline New Zealand & 1.09 & $1.11^{*}$ & $1.25^{* *}$ & $1.24^{* *}$ \\
\hline Sweden & $1.28^{*}$ & $1.33^{*}$ & $1.36^{* *}$ & $1.38^{* *}$ \\
\hline
\end{tabular}


(a) North America

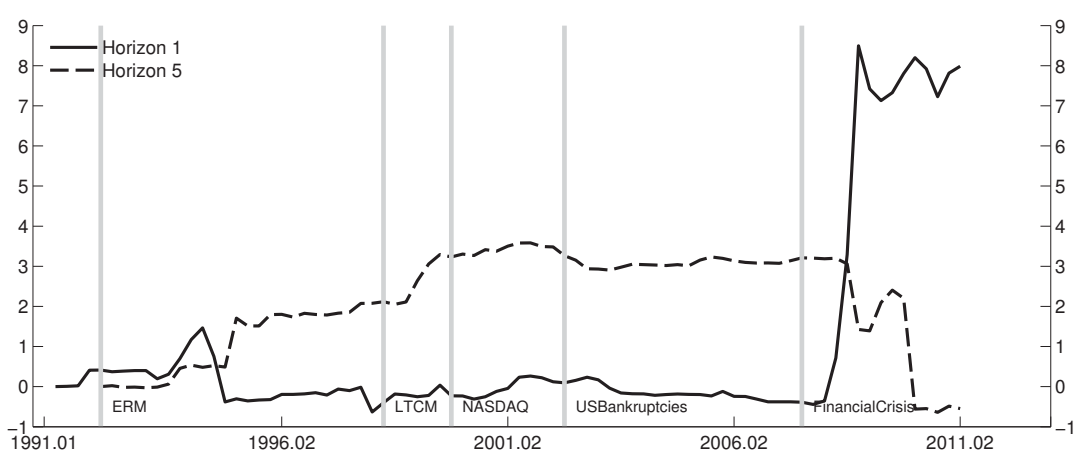

(b) South America

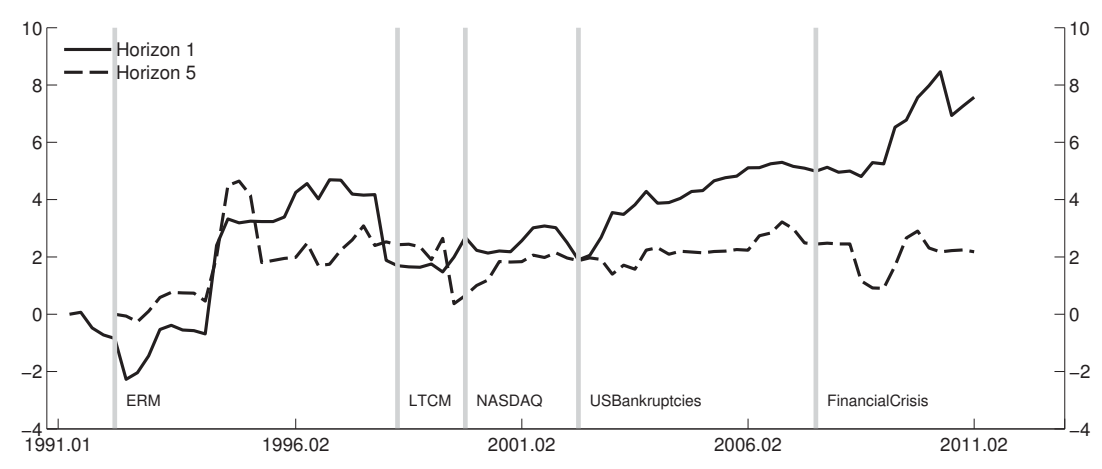

(c) Europe

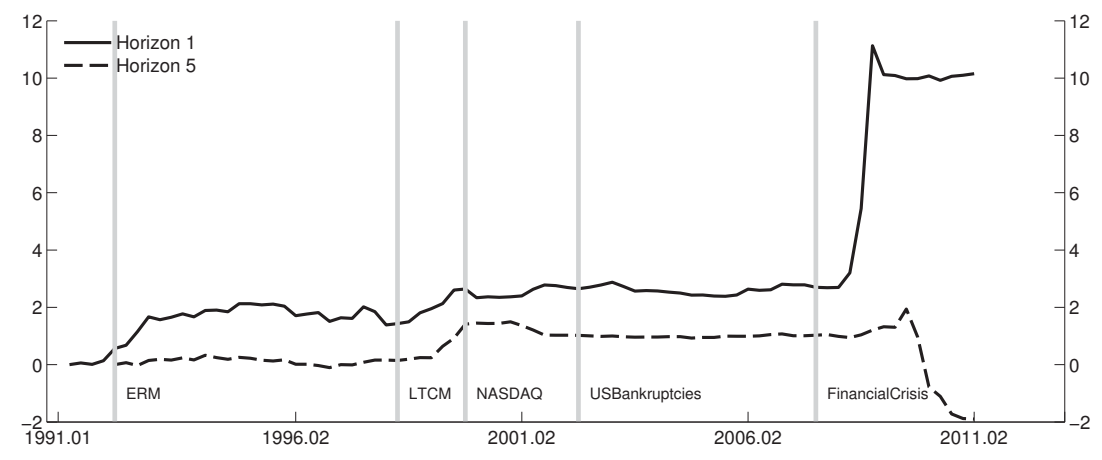

(d) Asia

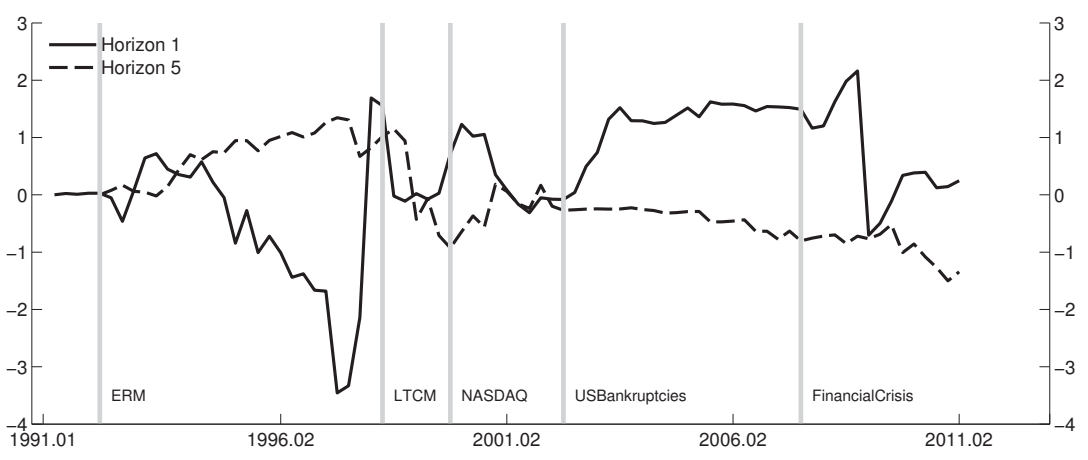

Figure 9. Relative historical forecast performance GDP - four regional components, RMSPE scores. The different plots report the average relative performance among countries within a geographical region. See also the notes to Figure 2. 
(a) North America

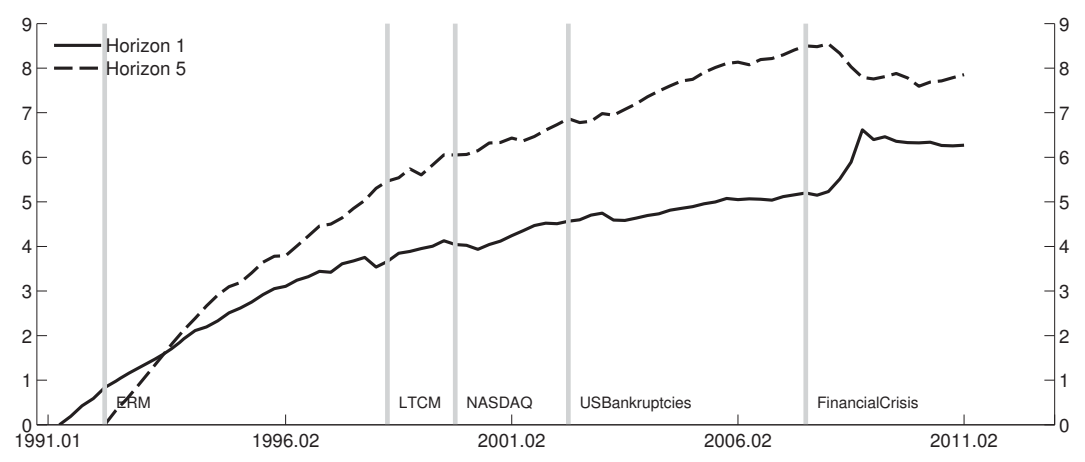

(b) South America

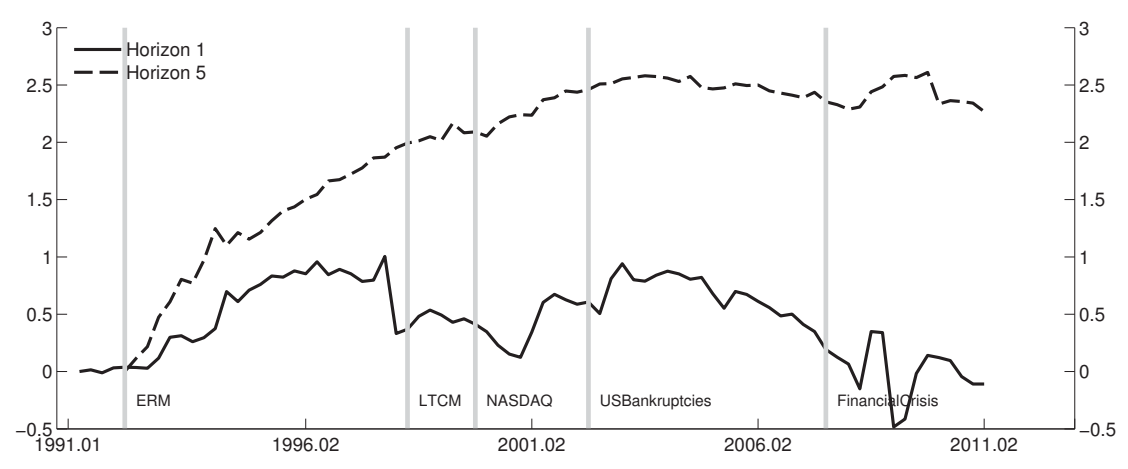

(c) Europe

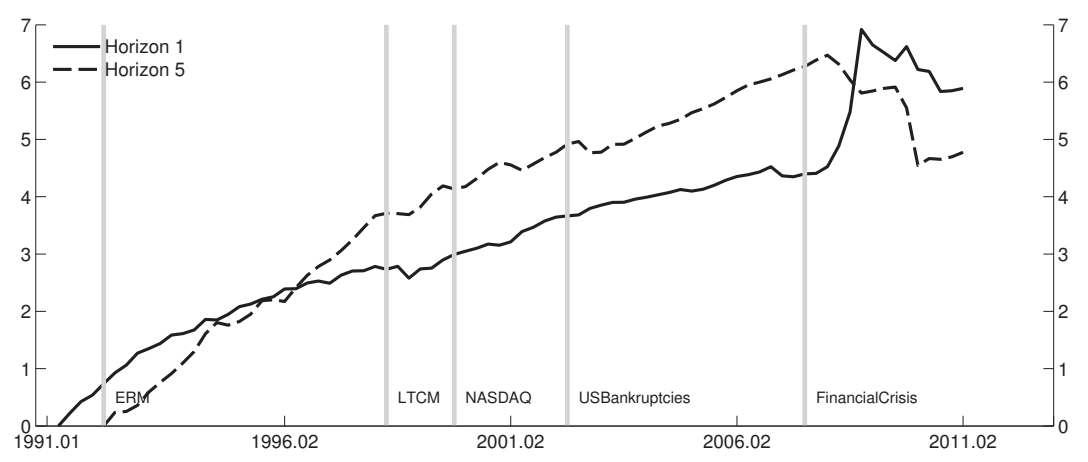

(d) Asia

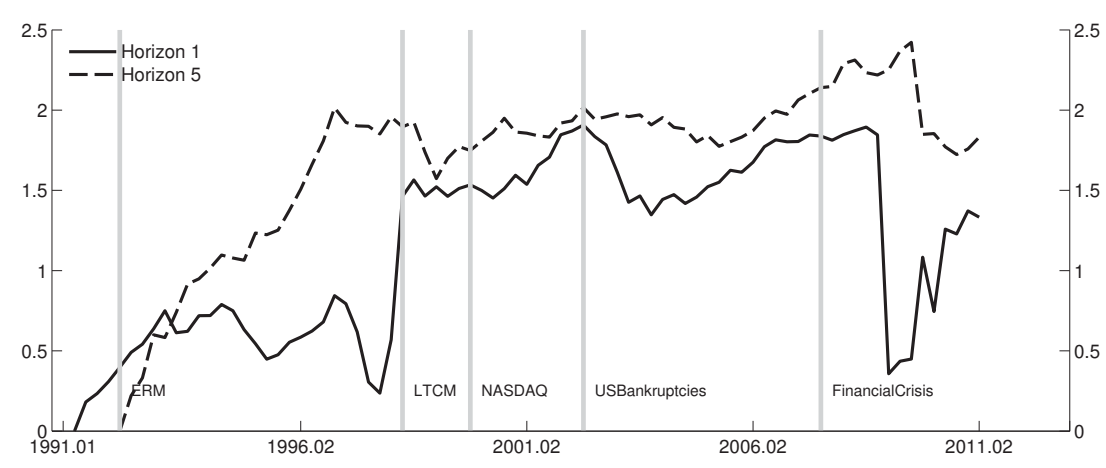

Figure 10. Relative historical forecast performance GDP - four regional components, CRPS scores. The different plots report the average relative performance among countries within a geographical region. See also the notes to Figure 2. 


\section{Appendix B The Gibbs sampling approach}

The three steps of the Gibbs sampler, described in Section 2.2, are iterated until convergence. Below we describe the three steps in more detail. The exposition follows Kim and Nelson (1999) (Chapter 8) closely, and we refer to their book for details.

For convenience, we repeat some notation: $\tilde{y}_{T}=\left[y_{1}, \cdots, y_{T}\right]^{\prime}, \tilde{f}_{T}=\left[f_{1}, \cdots, f_{T}\right]^{\prime}$, $H=\left[\lambda_{0}, \cdots, \lambda_{s}\right]$, and $p_{i}=\left[\rho_{1, i}, \cdots, \rho_{l, i}\right]$ for $i=1, \cdots, N$, and rewrite the state space model defined in equation 1 and 2 as:

$$
y_{t}=\Lambda F_{t}+\epsilon_{t}
$$

and

$$
F_{t}=A F_{t-1}+e_{t}
$$

where $F_{t}=\left[f_{t}^{\prime}, \cdots, f_{t-h}^{\prime}\right]^{\prime}, e_{t}=G u_{t}$, with $u_{t} \sim i . i . d . N(0, Q)$ and:

$$
A=\left(\begin{array}{cccc}
\phi_{1} & \phi_{2} & \cdots & \phi_{h} \\
I_{q} & 0 & \cdots & 0 \\
0 & I_{q} & \ddots & \vdots \\
0 & 0 & I_{q} & 0
\end{array}\right), \quad G=\left(\begin{array}{c}
I_{q} \\
0 \\
\vdots \\
0
\end{array}\right), \quad \Lambda=\left(\begin{array}{ll}
H & 0_{N, h-s}
\end{array}\right)
$$

Note that $h>s$ in our application.

We also allow for serially correlated idiosyncratic errors. In particular, we consider the case where $\epsilon_{t, i}$, for $i=1, \cdots, N$, follows independent $\mathrm{AR}(\mathrm{l})$ processes:

$$
\epsilon_{t, i}=p_{i} E_{t, i}+\omega_{t, i}
$$

where $\omega_{t, i}$ is the $\operatorname{AR}(1)$ residuals with $\omega_{t, i} \sim$ i.i.d.N $\left(0, \sigma_{i}^{2}\right)$,

$$
R=\left[\begin{array}{cccc}
\sigma_{1}^{2} & 0 & \cdots & 0 \\
0 & \sigma_{2}^{2} & \ddots & 0 \\
\vdots & \ddots & \ddots & \vdots \\
0 & \cdots & \cdots & \sigma_{N}^{2}
\end{array}\right]
$$

and $E_{t, i}=\left[\epsilon_{t-1, i}, \cdots, \epsilon_{t-l, i}\right]^{\prime}$.

\section{B.0.1 Step 1: $\tilde{f}_{T} \mid \tilde{y}_{T}, \Lambda, A, R, Q, p$}

We employ Carter and Kohn's multimove Gibbs sampling approach (see Carter and Kohn (1994)). Because the state space model given in equations 12 and 13 is linear and Gaussian, the distribution of $F_{T}$ given $\tilde{y}_{T}$ and that of $F_{t}$ given $F_{t+1}$ and $\tilde{y}_{t}$ for $t=T-1, \cdots, 1$ are also Gaussian:

$$
\begin{gathered}
F_{T} \mid \tilde{y}_{T} \sim N\left(F_{T \mid T}, P_{T \mid T}\right) \\
F_{t} \mid \tilde{y}_{t}, F_{t+1} \sim N\left(F_{t \mid t, F_{t+1}}, P_{t \mid t, F_{t+1}}\right), \quad t=T-1, T-2, \cdots, 1
\end{gathered}
$$

where

$$
\begin{aligned}
F_{T \mid T} & =E\left(F_{T} \mid \tilde{y}_{T}\right) \\
P_{T \mid T} & =\operatorname{Cov}\left(F_{T} \mid \tilde{y}_{T}\right) \\
F_{t \mid t, F_{t+1}} & =E\left(F_{t} \mid \tilde{y}_{t}, F_{t+1}\right)=E\left(F_{t} \mid F_{t \mid t}, F_{t \mid t+1}\right) \\
P_{t \mid t, F_{t+1}} & =\operatorname{Cov}\left(F_{t} \mid \tilde{y}_{t}, F_{t+1}\right)=\operatorname{Cov}\left(F_{t} \mid F_{t \mid t}, F_{t \mid t+1}\right)
\end{aligned}
$$


Given $F_{0 \mid 0}$ and $P_{0 \mid 0}$, we obtain $F_{T \mid T}$ and $P_{T \mid T}$ from the last iteration of the Gaussian Kalman filter:

$$
\begin{aligned}
F_{t \mid t-1} & =A F_{t-1 \mid t-1} \\
P_{t \mid t-1} & =A P_{t-1 \mid t-1} A^{\prime}+G Q G^{\prime} \\
K_{t} & =P_{t \mid t-1} \Lambda^{\prime}\left(\Lambda P_{t \mid t-1} \Lambda^{\prime}+R\right)^{-1} \\
F_{t \mid t} & =F_{t \mid t-1}+K_{t}\left(y_{t}-\Lambda F_{t \mid t-1}\right) \\
P_{t \mid t} & =P_{t \mid t-1}-K_{t} \Lambda P_{t \mid t-1}
\end{aligned}
$$

This means that at $t=T$ equation 26 and 27 above, together with equation 17 , is used to draw $F_{T \mid T}$.

We draw $F_{t \mid t, F_{t+1}}$ for $t=T-1, T-2, \cdots, 1$ based on 18 , where $F_{t \mid t, F_{t+1}}$ and $P_{t \mid t, F_{t+1}}$ are generated from the following updating equations:

$$
\begin{aligned}
& F_{t \mid t, F_{t+1}}=E\left(F_{t} \mid F_{t \mid t}, F_{t \mid t+1}\right) \\
& =F_{t \mid t}+P_{t \mid t}^{\prime} A\left(A P_{t \mid t} A^{\prime}+G Q G^{\prime}\right)^{-1}\left(F_{t+1}-A F_{t \mid t}\right) \\
& P_{t \mid t, F_{t+1}}=\operatorname{Cov}\left(F_{t} \mid F_{t \mid t}, F_{t \mid t+1}\right) \\
& =P_{t \mid t}+P_{t \mid t} A^{\prime}\left(A P_{t \mid t} A^{\prime}+G Q G^{\prime}\right) A P_{t \mid t}
\end{aligned}
$$

\section{B.0.2 Step 2: $A, Q \mid \tilde{y}_{T}, \tilde{f}_{T}, \Lambda, R, p$}

Conditional on $\tilde{f}_{T}$, equation 13 is independent of the rest of the model, and the distribution of $\mathrm{A}$ and $\mathrm{Q}$ are independent of the rest of the parameters of the model, as well as the data.

By abusing notation, we put the transition equation in SUR form and define:

$$
y=X \beta+\epsilon
$$

where $y=\left[f_{1}, \cdots, f_{T}\right]^{\prime}, X=\left[X_{1}, \cdots, X_{T}\right]^{\prime}, \epsilon=\left[\epsilon_{1}, \cdots, \epsilon_{T}\right]^{\prime}$ and $\beta=\left[\beta_{1}, \cdots, \beta_{q}\right]^{\prime}$, with $\beta_{k}=\left[\phi_{1, k}, \cdots, \phi_{h, k}\right]$ for $k=1, \cdots, q$. Further,

$$
X_{t}=\left(\begin{array}{cccc}
x_{t, 1} & 0 & \cdots & 0 \\
0 & x_{t, 2} & \ddots & \vdots \\
\vdots & \ddots & \ddots & \vdots \\
0 & \cdots & \cdots & x_{t, q}
\end{array}\right)
$$

with $x_{t, k}=\left[f_{t-1}^{\prime}, \cdots, f_{t-h}^{\prime}\right]$. Finally, $\epsilon \sim i . i . d . N\left(0, I_{q} \otimes Q\right) .{ }^{15}$

To simulate $\beta$ and $\mathrm{Q}$, we employ the independent Normal-Whishart prior:

$$
p(\beta, Q)=p(\beta) p\left(Q^{-1}\right)
$$

where

$$
\begin{gathered}
p(\beta)=f_{N}\left(\beta \mid \underline{\beta}, \underline{V}_{\beta}\right) \\
p\left(Q^{-1}\right)=f_{W}\left(Q^{-1} \mid \underline{v}_{Q}, \underline{Q}^{-1}\right)
\end{gathered}
$$

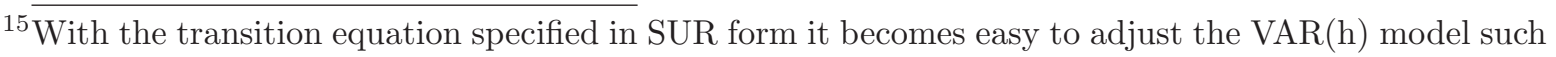
that different regressors enter the q equations of the $\operatorname{VAR}(\mathrm{h})$.
} 
The conditional posterior of $\beta$ is:

$$
\beta \mid y, Q^{-1} \sim N\left(\bar{\beta}, \bar{V}_{\beta}\right)_{I[s(\beta)]}
$$

with

$$
\bar{V}_{\beta}=\left(\underline{V}_{\beta}^{-1}+\sum_{t=1}^{T} X_{t}^{\prime} Q^{-1} X_{t}\right)^{-1}
$$

and

$$
\bar{\beta}=\bar{V}_{\beta}\left(\underline{V}_{\beta}^{-1} \underline{\beta}+\sum_{t=1}^{T} X_{t}^{\prime} Q^{-1} y_{t}\right)
$$

$I[s(\beta)]$ is an indicator function used to denote that the roots of $\beta$ lie outside the unit circle.

The conditional posterior of $Q^{-1}$ is:

$$
Q^{-1} \mid y, \beta \sim W\left(\bar{v}_{Q}, \bar{Q}^{-1}\right)
$$

with

$$
\bar{v}_{Q}=\underline{v}_{Q}+T
$$

and

$$
\bar{Q}=\underline{Q}+\sum_{t=1}^{T}\left(y_{t}-X_{t} \beta\right)\left(y_{t}-X_{t} \beta\right)^{\prime}
$$

B.0.3 Step 3: $\Lambda, R, p \mid \tilde{y}_{T}, \tilde{f}_{T}, A, Q$

Conditional on $\tilde{f}_{T}$, and given our assumption of $\mathrm{R}$ being diagonal, equation 12 result in $\mathrm{N}$ independent regression models.

However, to take into account serially correlated idiosyncratic errors, and still employ standard Bayesian techniques, we need to transform equation 12 slightly.

Thus, for $i=1, \cdots, N$, conditional on $\mathrm{p}$, and with $l=1$, we can rewrite equation 12 as:

$$
y_{t, i}^{*}=\Lambda_{i} F_{t}^{*}+\omega_{t, i}
$$

with $y_{t, i}^{*}=y_{t, i}-p_{1, i} y_{t-1, i}$, and $F_{t}^{*}=F_{t}-p_{1, i} F_{t-1}$, and $\Lambda_{i}$ being the i-th row of $\Lambda$.

From 40 we can then simulate the parameters $\Lambda_{i}$ and $R_{i, i}=\sigma_{i}^{2}=\frac{1}{h_{i}}$ using standard independent Normal-Gamma priors (for notational convenience we drop the subscript i from the expressions below): ${ }^{16}$

$$
p(\Lambda, h)=p(\Lambda) p(h)
$$

where

$$
\begin{aligned}
& p(\Lambda)=f_{N}\left(\Lambda \mid \underline{\Lambda}, \underline{V}_{\Lambda}\right) \\
& p(h)=f_{G}\left(h \mid \underline{s}^{-2}, \underline{v}_{h}\right)
\end{aligned}
$$

The conditional posterior of $\Lambda$ is:

$$
\Lambda \mid \tilde{y}, h, p \sim N\left(\bar{\Lambda}, \bar{V}_{\Lambda}\right)
$$

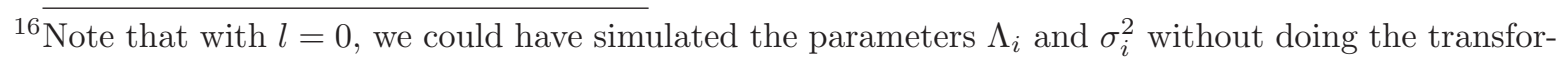
mation of variables described above.
} 
with;

$$
\bar{V}_{\Lambda}=\left(\underline{V}_{\Lambda}^{-1}+h \sum_{t=1}^{T} F_{t}^{*^{\prime}} F_{t}^{*}\right)^{-1}
$$

and

$$
\bar{\Lambda}=\bar{V}_{\Lambda}\left(\underline{V}_{\Lambda}^{-1} \underline{\Lambda}+h \sum_{t=1}^{T} F_{t}^{*^{\prime}} y_{t}^{*}\right)
$$

The conditional posterior for $h$ is:

$$
h \mid \tilde{y}, \Lambda, p \sim G\left(\bar{v}_{h}, \bar{s}^{-2}\right)
$$

with

$$
\bar{v}_{h}=\underline{v}_{h}+T
$$

and

$$
\bar{s}=\frac{\sum_{t=1}^{T}\left(y_{t}^{*}-\Lambda F_{t}^{*}\right)^{\prime}\left(y_{t}^{*}-\Lambda F_{t}^{*}\right)+\underline{v}_{h} \underline{s}^{2}}{\bar{v}_{h}}
$$

Finally, conditional on $\Lambda$ and $\mathrm{h}$, the posterior of $\mathrm{p}$ depends upon its prior, which we assume is a multivariate Normal, i.e.:

$$
p(p)=f_{N}\left(p \mid \underline{p}, \underline{V}_{p}\right)
$$

Accordingly, the conditional posterior for $\mathrm{p}$ is:

$$
p \mid \tilde{y}, \Lambda, h \sim N\left(\bar{p}, \bar{V}_{p}\right)_{I[s(p)]}
$$

with

$$
\bar{V}_{p}=\left(\underline{V}_{p}^{-1}+h \sum_{t=1}^{T} E_{t}^{\prime} E_{t}\right)^{-1}
$$

and

$$
\bar{p}=\bar{V}_{p}\left(\underline{V}_{p}^{-1} \underline{p}+h \sum_{t=1}^{T} E_{t}^{\prime} \epsilon_{t}\right)
$$

\section{B.0.4 Prior specifications and initial values}

The model is estimated using two-step parameter estimates (see Section 2.2) as priors. We label these estimates OLS. In particular, for equations 32 and 33 we set $\beta=\beta^{O L S}$, $\underline{V}^{\beta}=V_{\beta}^{O L S} \times 3, \underline{Q}=Q^{O L S}$ and $\underline{v}_{Q}=10$. For equations 42,43 and 50 we set $\underline{v}_{h}=10$, $\underline{s}^{2}=s^{2, O L S}, \underline{\Lambda}=\left[\lambda_{0}^{O L S}: 0_{N, h-s-1}\right]$ and $\underline{V}^{\Lambda}=\left[\left(I_{s} \times 3\right) \otimes V_{\lambda_{0}^{O L S}}\right] . \underline{p}=0$, and $\underline{V}^{p}=0.5$.

In sum, these priors are reasonable uninformative, but still proper. We have also experimented with other prior specifications, e.g., using Minnesota style prior for the transition equation parameters, and setting $\underline{\Lambda}=0$. This yields similar results as those reported in the main text. However, the variables in our sample display very different unconditional volatilities. The prior specification should accommodate this feature.

The Gibbs sampler is initialized using parameter values derived from the two-step estimation procedure. Parameters not derived in the two-step estimation (i.e. $p$ and $\left.\lambda_{1}, \cdots, \lambda_{s}\right)$ are set to 0 . 
In this model, a subtle issue arises for the $t=0$ observations (i.e. lags of the dynamic factors and the idiosyncratic errors at time $t=1$ ). However, since we assume stationary errors in this model, the treatment of initial conditions is of less importance. Accordingly, we follow common practice and work with the likelihood based on data from $t=h+1, \cdots, T$. 